\title{
A review of recent developments in retinitis pigmentosa genetics, its clinical features, and natural course
}

\author{
Eleftherios Loukovitis ${ }^{1,2}$, Stoimeni Anastasia ${ }^{1,3}$, Paris Tranos ${ }^{1}$, Miltos Balidis ${ }^{1}$, Solon Asteriadis ${ }^{1}$, Vakalis Thanos ${ }^{1}$, Sousouras \\ Thanos ${ }^{1}$, George Anogeianakis ${ }^{1,4}$ (D) \\ ${ }^{1}$ Ophthalmica Eye Institute, Thessaloniki, Greece \\ 2 Department of Ophthalmology, 424 General Military Hospital, Thessaloniki, Greece \\ ${ }^{3}$ Faculty of Medicine, Aristotle University of Thessaloniki, Thessaloniki, Greece \\ ${ }^{4}$ Association for Training in Biomedical Technology, Thessaloniki, Greece
}

\begin{abstract}
Background: Retinitis pigmentosa (RP), an inherited degenerative ocular disease, is considered the most common type of retinal dystrophy. Abnormalities of the photoreceptors, particularly the rods, and of the retinal pigment epithelium, characterizes this disease. The abnormalities progress from the midperiphery to the central retina. We here reviewed the developments in RP genetics in the last decade, along with its clinical features and natural course.

Methods: The present review focused on articles in English language published between January 2008 and February 2020, and deposited in PubMed/MEDLINE and Google Scholar databases. We searched for articles reporting on the clinical manifestations and genes related to both syndromic and non-syndromic RP. We screened and analyzed 139 articles, published in the last decade, referring to RP pathogenesis and identified, summarized, and highlighted the most significant genes implicated in either syndromic or non-syndromic RP pathogenesis, causing different clinical manifestations.

Results: Recent literature revealed that approximately 80 genes are implicated in non-syndromic RP, and 30 genes in syndromic forms, such as Usher syndrome and Bardet-Biedl syndrome (BBS). Moreover, it is estimated that 27 genes are implicated in autosomal dominant RP (adRP), 55 genes in autosomal recessive RP (arRP), and 6 genes in X-linked RP ( $x$ IRP), causing different RP phenotypes. Characteristically, $R H O$ is the most prevalent adRP- and arRP-causing gene, and RPGR the most common xIRP-causing gene. Other important genes are PRPH2, RP1, CRX, RPE65, ABCA4, CRB1, and USH2A. However, different phenotypes can also be caused by mutations in the same gene.

Conclusions: The genetic heterogeneity of RP necessitates further study to map the exact mutations that cause more severe forms of RP, and to develop and use appropriate genetic or other effective therapies in future.
\end{abstract}

\section{KEY WORDS}

retinitis pigmentosa, genes, syndromic RP, non-syndromic RP, retinal dystrophy, genetics, Bardet-Biedl syndrome, autosomal dominant, heterogeneity, RP, photoreceptor, Usher syndrome, autosomal recessive RP

Copyright (c) 2020, Author(s). This is an open-access article distributed under the terms of the Creative Commons Attribution-Non Commercial 4.0 International License (http://creativecommons.org/licenses/by-nc/4.0/) which permits copy and redistribute the material just in noncommercial usages, provided the original work is properly cited.

Correspondence to: Professor George Anogeianakis, Ophthalmica Eye Institute, Vas Olgas 196 \& Ploutonos 27, 54655 Thessaloniki, Greece. E-mail: anogian@auth.gr

How to cite this article: Loukovitis E, Anastasia S, Tranos P, Balidis M, Asteriadis S, Vakalis Th, Sousouras Th, Anogeianakis G. A review of recent developments in retinitis pigmentosa genetics, its clinical features, and natural course. Med Hypothesis Discov Innov Ophthalmol. 2020 Winter; 9(4): 231-254. DOI: https://doi.org/10.51329/mehdiophthal1410

\section{INTRODUCTION}

Retinitis pigmentosa (RP) is an inherited eye disease that manifests with various dystrophic and degenerative symptoms. It is thought to be the most common type of retinal dystrophy [1-5], and affects millions of individuals worldwide, including over 200,000 individuals in the USA $[6,7]$. RP was first described by Van Trigt in 1853 (through an ophthalmoscope) and was recognized as a pathological condition by Donders, 4 years later [7]. Although retinitis 
involves inflammation of the retina, RP refers to a hereditary condition without inflammation [8].

Degeneration of rods and cones, and of the retinal pigment epithelium (RPE) is typical of RP disorders. The degeneration usually develops at the middle $\left(50^{\circ}\right.$ to $\left.90^{\circ}\right)$ of the periphery of the retina and progresses towards the central region of the retina, frequently affecting the macula and fovea [2, 5-7]. Clinically, it differs from other retinal diseases, such as Leber congenital amaurosis (LCA), macular dystrophies (MD), and cone-rod dystrophies (CRD), which are inherited retinal diseases (IRDs) that present at birth or early in postnatal life. It is also clinically distinct from non-progressive conditions, including achromatopsia and congenital stationary night blindness (CSNB) [7]. There are several other ocular conditions associated with RP. Refractive error or nystagmus may occur in early-onset RP, whereas macular hole, epiretinal membrane formation, and cystoid macular edema (CME) may be present in more than $50 \%$ of RP patients. In addition, posterior subcapsular cataracts are present in up to $45 \%$ of RP patients, secondary retinal vasoproliferative tumors, vitreous cysts in $6 \%$ of RP patients, and optic nerve head and fiber layer drusen in approximately $9 \%$ of RP patients [7].

The present review sought to present the various types of $\mathrm{RP}$, and the symptoms and retinal findings that appear progressively at each stage of the disease. In addition, we review the genetic heterogeneity of RP, referring to the genes most commonly implicated in different forms of the disease. We also analyze the clinical manifestations of disease-causing mutations of the most important pathogenic genes.

\section{METHODS}

We screened the PubMed/MEDLINE and Google Scholar databases for articles referring to clinical manifestations and genes related to both syndromic and non-syndromic RP. The present review focused on articles in the English language published between January 2008 and February 2020. Keyword combinations of "retinitis pigmentosa," "genetics," "genes", and "(non) syndromic" were used.

\section{RESULTS}

In total, 105 articles were analyzed, with a focus on the most recent literature. Further bibliographic research on the reference list of these articles revealed another 34 related articles that were also analyzed and included in the review. Based on the reviewed literature, this article focuses on the types and clinical manifestations of RP, and summarizes the key genes and disease-causing mutations associated with the pathogenesis of syndromic and nonsyndromic RP. Table 1 summarizes the genes reported to date as causes of Usher syndrome. Table 2 summarizes the genes reported to cause Bardet-Biedl syndrome (BBS) in the current literature. Table 3 summarizes the genes reported to cause autosomal dominant (ad) RP in the current literature. Table 4 summarizes the genes reported to cause autosomal recessive (ar) RP in the current literature. Table 5 summarizes the overlap between genes causing RP and causing other IRDs, and Table 6 summarizes all abbreviations used in the text.

\section{DISCUSSION}

TYPES OF RP

\section{Non-syndromic RP: Symptoms and retinal findings}

RP may occur alone without other clinical manifestations, and is then known as non-syndromic RP, or it may occur along with developmental abnormalities, neurosensory disorders, or various combined clinical phenotypes, and is then known as syndromic (or systemic) RP [9]. Approximately $70-80 \%$ of all RP cases are non-syndromic. The worldwide prevalence of RP in patients without systemic manifestations is estimated to be 1 in 4000 [1-4, $9,10]$, although it ranges from 1:9000 to 1:750, depending on the geographic location [7]. For instance, it is estimated to be 1:3800 in China [1].

Non-syndromic RP is inherited in an ad form (adRP; 20$40 \%$ ), ar form (arRP; 30-50\%), or in an X-linked form (xIRP) $(5-15 \%)[1-4,9,11]$. Non-Mendelian inheritance patterns accounts for only a minor proportion of cases. These include digenic, mitochondrial, and de novo mutations [3, $4,9,11,12]$. In addition, approximately $30 \%$ of all nonsyndromic RP cases are sporadic, while most exhibit an apparently autosomal recessive inheritance [1, 3, 12]. However, these percentages vary among populations [3]. XIRP appears to be the most severe form of RP, as it progresses more aggressively and is characterized by early-onset. Clinically, it is more severe in men than in women [10]. AdRP cases are characterized by the best long-term prognosis in terms of retaining central vision [7]. In a previous report, by the age of 20 years, $87 \%$ of patients with xIRP and $75 \%$ of patients with adRP had symptoms, whereas this proportion was only $61 \%$ for arRP and $64 \%$ with simplex cases. By the age of 30 years, all xIRP patients, $89 \%$ of adRP patients, $74 \%$ of arRP patients, and $79 \%$ of simplex cases presented with symptoms [8].

Hence, adRP has been reported to have the best prognosis, whereas XIRP is the most aggressive form, and in XIRP all patients aged 50 years and older have a visual acuity worse than 20/200. In addition, intermediate severity is present in patients with arRP. However, other reports suggest that genetic subtypes do not affect central visual impairment [8]. 


\section{Syndromic RP}

Approximately $20-30 \%$ of RP cases present with systemic manifestations. Syndromic RP appears in more than 30 different syndromes. Overall $20-40 \%$ of these cases are inherited in a recessive manner and $10-20 \%$ appear in conjunction with Usher syndrome [9]. It is a major cause of combined deafness and blindness, and is responsible for approximately $50 \%$ of all cases with these symptoms. It affects $1: 12,000$ to $1: 30,000$ individuals in different populations and has a prevalence of 5-6 per 100,000 individuals in the USA and Northern Europe [12, 13].

It is divided into three types. Type I, which is present at birth, is the most severe form, and is characterized by progressive hearing loss and is associated with vestibular ataxia. Type II, which is non-progressive, congenital, and mild to moderate in severity, presents with retinal degeneration in older age, but without vestibular dysfunction. Type III, which is progressive, with normal hearing present in youth and with gradual hearing loss during later years $[9,12,13]$. Mental and behavioral disorders, including schizophrenia-like psychosis, have also been reported in Usher patients [13]. There are 1215 genes that can cause Usher's syndrome, with different mutations causing each type, while some mutations may cause either RP without hearing loss or deafness without RP [9]. Genes implicated in type I Usher syndrome are MYO7A (USH1B; 11q13.5), CDH23 (USH1D; 10q22.1), PCDH15 (USH1F; 10q21.1), USH1C (USH1C; 11p15.1), USH1G (USH1G; 17q25.1), CIB2 (15q25.1), and CLRN1 (3q25.1). Those involved in type II are USH2A (USH2A; 1q41), GPR98 (USH2C; 5q14.3), and DFNB31 (USH2; 9q32). Genes involved in type III are HARS (USH3A; 5q31.3), and ABHD12 (2p11.21) [12, 14]. Table 1 summarizes the genes reported to date as causes of Usher syndrome.

Bardet-Biedl syndrome (BBS) is a syndrome that may involve syndromic RP. It is characterized by a fundus abnormality with early macular involvement, consisting of a non-typical pigmentary retinal dystrophy. BBS accounts for as many as $5-6 \%$ of RP cases [9]. The prognosis for affected children is poor, as legal blindness appears at the age of 15.5 years. Night blindness is also observed in the first decade. BBS is associated with kidney disease, polydactyly, obesity, renal dysfunction, hypogonadotropic hypogonadism (in male patients), genitourinary malformations (in female patients), cognitive impairment, and developmental delay. Mortality is frequently associated with renal disease, which is inherited in an autosomal recessive pattern, affecting 1:120,000 Caucasians [12]. Mitochondrial diseases or degenerative cerebellar diseases may also be associated with BBS pathogenesis $[6,7]$. These manifestations vary in BBS patients depending on the gene and the exact mutation implicated in BBS pathogenesis in each individual [7]. Twenty one genes have been identified in BBS, including BBS1 (11q13; implicated in $40 \%$ of BSS patients), BBS2 (16q12.2; implicated in 20\% of BSS patients), ARL6 (causing BBS3; 3q11.2), BBS4 (15q24.1; implicated in 3-6\% of BSS patients), BBS5 (2q31.1; implicated in $2 \%$ of BSS patients), MKKS (causing BBS6; 20p12.2), BBS7 (4q27), TTC8 (causing BBS8; 14q32.11), B1 (causing BBS9; 7p14.3), BBS10 (12q21.2), TRIM32 (causing BBS11; 9q33.1), BBS12 (4q27), MKS1 (causing BBS13) (17q22), CEP290 (causing BBS14; 12q21.32), BBIP1 (10q25.2), IFT27 (22q12.3), INPP5E (9q34.3), KCNJ13 (2q37.1), LZTFL1 (3p21.31), NPHP1 (2q13), and SDCCAG8 (1q43) [12, 14]. These genes cause approximately $70 \%$ of cases, and most of the mutations are associated with autosomal recessive patterns of inheritance [9]. Further BBS-associated genes are yet to be identified, as approximately $30 \%$ of BBS cases are not associated with any of the 21 genes reported to date [12]. Table 2 summarizes the genes reported to cause BBS in the current literature. Other clinically important syndromic forms of RP are Bassen-Kornzweig syndrome (abetalipoproteinemia), Refsum's disease (phytanic acid oxidase deficiency), and $\alpha$-tocopherol transport protein deficiency (vitamin $E$ deficiency) [9].

Table 1. Genes Reported to Cause Usher Syndrome

\begin{tabular}{|l|l|}
\hline ABHD12 (Abhydrolase Domain Containing 12, Lysophospholipase) & $2 \mathrm{p} 11.21[13]$ \\
\hline CDH23 (Cadherin Related 23) & $10 q 22.1[12,13]$ \\
\hline CIB2 (Calcium And Integrin Binding Family Member 2) & $15 q 25.1[13]$ \\
\hline CLRN1 (Clarin 1) & $3 q 25.1[13]$ \\
\hline DFNB31 (Deafness, Autosomal Recessive 31) & $9 q 32[12,13]$ \\
\hline GPR98 (G Protein-Coupled Receptor 98) & $5 q 14.3[12,13]$ \\
\hline HARS (Histidyl-TRNA Synthetase) & $5 q 31.3[13]$ \\
\hline MYO7A (Myosin VIIA) & $11 q 13.5[12,13]$ \\
\hline PCDH15 (Protocadherin Related 15) & $10 q 21.1[12,13]$ \\
\hline USH1C (USH1 Protein Network Component Harmonin) & $11 p 15.1[12,13]$ \\
\hline USH1G (USH1 Protein Network Component Sans) & $17 q 25.1[12,13]$ \\
\hline USH2A (Usherin) & $1 q 41[12,13]$ \\
\hline
\end{tabular}




\section{Symptoms of RP}

$\mathrm{RP}$ results in progressive vision loss and blindness [1]. The age of onset ranges from early childhood to midadulthood [15]. Problems with dark adaptation often manifest during adolescence, while visual loss in the midperipheral field is usually evident in the second and third decades of life. Despite this general rule, the age of onset varies among patients. Early onset RP usually progresses more rapidly. Some patients therefore develop visual loss by the age of 30 , while others remain asymptomatic until the fifth decade of life [7]. The diagnosis of early-onset RP is based on the presence of mid-stage RP symptomatology after the age of 2 years. However, the diagnosis of lateonset RP requires that the first symptoms of RP present in midlife or later $[5,6]$.

Nevertheless, it is difficult to determine the age of RP onset accurately, because many patients, and particularly children, compensate for the loss of peripheral vision. In addition, the artificial illumination of nighttime environments tends to mask possible problems with dark adaptation [7]. In extreme cases, RP progresses rapidly over the course of two decades. At the other extreme, the disease may present with slow progression and may never lead to blindness [5]. RP is a very common cause of visual impairment in patients aged 30-60 years, with higher parental consanguinity than other genetic diseases, such as Stargardt disease (STGD) and retinopathy of prematurity [16].

Typically, RP is present during the first years of life. However, it may also appear in early adolescence or even

later in life. Often, night blindness is not evident in young patients, and only becomes apparent between 12 and 18 years old. There are also defects in the visual field in dim light, whereas minor defects appear in visual acuity, and color vision is normal. Thus, it is difficult to diagnose RP at an early stage, as symptoms may not yet have manifested, particularly in cases where there are no other family members affected with RP. Scotopic visual fields present scotomas and electroretinograms (ERGs) may be normal when RP has not yet progressed, while a decreased amplitude of the $b$-wave on ERG may be present in dark conditions [5-7].

In the mild stages, night blindness is obvious; there is loss in the peripheral visual field under photopic conditions, dyschromatopsia, particularly in terms of blue and yellow, and photophobia in diffuse light. Visual acuity is decreased, as macular involvement may also be present, or because of subcortical posterior cataract, which should be removed even in the presence of macular involvement. Atrophy of the retina is evident upon fundus examination at this stage, along with minute bone spicule-shaped pigment deposits at the middle periphery. The retinal vessels appear narrow, while the optic disc is rather pale. Scotopic ERG (rods), in most cases, cannot be recorded. ERG cone responses are markedly diminished. Mild peripheral scotomas are evident in visual field tests, frequently progressing to the extreme periphery or the macula [57].

Table 2. Genes Reported to Cause Bardet-Biedl Syndrome

\begin{tabular}{|l|l|}
\hline ARL6 (ADP Ribosylation Factor Like GTPase 6) & Chromosome \\
\hline BBIP1 (BBSome Interacting Protein 1) & $3 q 11.2[12,13]$ \\
\hline BBS1 (Bardet-Biedl Syndrome 1) & $10 \mathrm{q} 25.2[13]$ \\
\hline BBS2 (Bardet-Biedl Syndrome 2) & $11 \mathrm{q} 13[12,13]$ \\
\hline BBS4 (Bardet-Biedl Syndrome 4) & $16 \mathrm{q} 12.2[12,13]$ \\
\hline BBS5 (Bardet-Biedl Syndrome 5) & $15 \mathrm{q} 24.1[12,13]$ \\
\hline BBS7 (Bardet-Biedl Syndrome 7) & $2 \mathrm{q} 31.1[12,13]$ \\
\hline BBS9 (Bardet-Biedl Syndrome 9) & $4 \mathrm{q} 27[12,13]$ \\
\hline BBS10 (Bardet-Biedl Syndrome 10) & $7 \mathrm{p} 14.3[12,13]$ \\
\hline BBS12 (Bardet-Biedl Syndrome 12) & $12 \mathrm{q} 21.2[12,13]$ \\
\hline CEP290 (Centrosomal Protein 290) & $4 \mathrm{q} 27[12,13]$ \\
\hline IFT27 (Intraflagellar Transport 27) & $12 \mathrm{q} 21.32[12,13]$ \\
\hline KCNJ13 (Potassium Inwardly Rectifying Channel Subfamily J Member 13) & $22 \mathrm{q} 12.3[13]$ \\
\hline LZTFL1 (Leucine Zipper Transcription Factor Like 1) & $2 \mathrm{q} 37.1[13]$ \\
\hline NPHP1 (Nephrocystin 1) & $3 \mathrm{p} 21.31[13]$ \\
\hline MKKS (McKusick-Kaufman Syndrome) & $2 \mathrm{q} 13[13]$ \\
\hline MKS1 (MKS Transition Zone Complex Subunit 1) & $20 \mathrm{p} 12.2[12,13]$ \\
\hline TRIM32 (Tripartite Motif Containing 32) & $17 \mathrm{q} 22[12,13]$ \\
\hline TTC8 (Tetratricopeptide Repeat Domain 8) & $9 \mathrm{q} 33.1[12,13]$ \\
\hline SDCCAG8 (SHH Signaling And Ciliogenesis Regulator SDCCAG8) & $14 \mathrm{q} 32.11[12,13]$ \\
\hline
\end{tabular}


The end stage of RP is characterized by the inability of RP patients to move autonomously because of peripheral vision loss and classic tunnel vision. Reading is difficult or impossible, photophobia is severe, ERG is unrecordable, and fundus examination reveals pigment deposits in the central retina, particularly the macula. The optic disc appears to have a waxy pallor, and the retinal vessels are thin. Chorioretinal atrophy is evident on fluorescein angiography, both at the periphery and at the foveomacular area [5-7].

Hence, nyctalopia and difficulties in adapting to changes in brightness may be present in the early stages of $\operatorname{RP}[1,5,9]$. This is considered to be the earliest symptom of RP [5] which, eventually, develops into "tunnel vision" (loss of peripheral vision) and, finally, legal or complete blindness [2, 5-7, 9]. The loss of photoreceptors in the outer retina, the rods that mediate vision at night and generally scotopic conditions, and the cones that mediate color vision and vision under generally photopic conditions may cause several visual symptoms. On the other hand, cells in the inner retina, including bipolar cells, amacrine cells, and ganglion cells, are affected later [9].

Most frequently, nyctalopia usually starts in the first decade of life, while peripheral visual field defects are present in the second decade of life and, in most cases, by the fourth or fifth decade of life, visual acuity is completely lost. Nevertheless, the course of RP in female carriers is characterized by variable clinical symptoms, and visual impairment usually appears in early middle age [10]. Anatomical defects of the central retina may manifest early during the progression of the disease. However, the central retina and function of the macula are relatively free until the late stages of the disease. Eventually, cone degeneration causes poor visual acuity until the fourth decade of life, although most patients retain the ability to perceive light. This is associated with residual macular function [7].

As already mentioned, another characteristic feature of $\mathrm{RP}$ is the progressive loss of the visual field, presenting with bilateral symmetry and beginning with scotomas in the mid-peripheral areas. These isolated scotomas gradually coalesce into an annular scotoma that extends both in the outward and inward directions. In addition, progression of concentric visual field loss, which follows an arcuate pattern and proceeds in the superior to inferior direction of the retina, has been reported $[7,9]$.

Another common but often-neglected symptom of RP is photopsia. It can occur early in RP progression, but it may be highly disturbing in advanced RP. Photopsia may result from the absence of afferent nerve impulses due to photoreceptor degeneration or may be the result of spontaneous self-signaling due to inner retinal remodeling $[5,7]$.

In addition, other symptoms that characterize RP patients are photophobia [5, 7], myopia, and hyperopia. Both myopia and hyperopia, particularly high forms, are also more prevalent in patients with RP. Hyperopia among RP patients mostly appears with mutations in CRB1, NR2E3, or LRAT. In contrast, myopia is more related to Usher syndrome. It is also associated with the RBP3, ZNF408, and $R P 1$ genetic subtypes in arRP and with the $R P 2$ and $R P G R$ genetic subtypes in xIRP [7].

At the cellular level, RP is a progressive disability resulting from the loss of rods. In the beginning, it compromises night vision by affecting the mid-peripheral retina, which has abundant rod photoreceptors. Subsequently, it progresses into the central retina, eventually eliminating cones either directly due to the disease process or indirectly through rod death [6, 7]. Finally, the disease onset, progression, retinal appearance (i.e., rod versus cone involvement, involvement of the RPE and other types of retinal cells, such as bipolar cells), secondary symptoms (e.g., CME), and final visual outcome vary widely, even among blood relatives $[1,3,6,7]$.

\section{Retinal findings of RP}

Upon examination, the main retinal manifestations include bone-spicule formations and thinning of blood vessels, a waxy pallor of the optic nerve, and changes in structure. Shortening of the photoreceptor outer segments (OSs) imaged by optical coherence tomography $(\mathrm{OCT})$, reduced visual fields, and reduced and/or abnormal ERG $[1,2,6,10,11]$, such as the amplitude diminution of a- and b-waves are paraclinical manifestations of RP [5]. This indicates characteristic loss mostly of rod photoreceptor function in the early stages of RP [7]. OCT, visual field examination, and ERG are non-invasive procedures that are not time-consuming and can be easily performed, even in adolescents. In particular, OCT and full-field ERG (ffERG) provide objective and detailed information about central retinal structure and function. Such information contributes to both the detection and identification of the clinical phenotype of RP [17].

In the early stages, vascular thinning is minimal, bonespicule formations are, at most, sparse, and the optic disc is mostly normal in appearance; thus, a fundus examination may appear normal. In addition, some RP patients may have non-specific abnormalities, such as broadening of the foveal reflex, irregular reflexes from the internal limiting membrane, or whitish lesions. However, some patients develop dust-like pigmentation, while 
others develop nummular hyperpigmentation, which may vary among patients, without reflecting the severity of the disease. Melanin pigment deposits are formed by RPE cells with bone-spicule pigmentation, which are detached from Bruch's membrane after photoreceptor degeneration and intraretinal migration. Bone-spicule formations are most often evident in the rod-rich mid-periphery [5, 7].

Vascular thinning in the retina of RP patients seems to be the result of photoreceptor loss, leading to reduced metabolic demand. An alternative explanation is that it is the result of a hyperoxic state of the inner retina, provoking loss of oxygen-consuming photoreceptors, leading to retinal vessel thinning and reduced blood flow. A third explanation suggests that vessel narrowing is caused by thickening of the extracellular matrix, where the vessels are embedded together with the RPE cells that have migrated [7].

Moreover, vascular remodeling and subsequent vessel attenuation are attributed to the decreased metabolism of the inner retinal layers [7]. Other studies suggest that retinal atrophy is associated with a reduction in ocular blood flow $[5,7]$. Thus, it remains unclear whether RPassociated vascular changes are secondary to neuroretinal remodeling or whether they are of primary importance for RP development. Additionally, the vasoconstrictor endothelin-1 may be involved in RP development. Finally, the waxy pallor, which typically develops in the optic disc, is due to the glial cells situated either on the surface or inside the optic disc, causing enhanced light reflectance [7].

\section{GENETIC ASPECTS OF RP PATHOGENESIS}

\section{Genes associated with RP pathogenesis}

The term IRDs includes several different diseases, with more than 190 genes involved in some form of IRD $[6,18]$. RP seems to be associated with dozens of different genetic defects [7]. Hence, at a genetic level, RP is thought to be complicated and heterogeneous [1, 2, 10], while it accounts for approximately half of IRD cases. Nonsyndromic RP has been associated with more than 80 genes $[3,6,7]$, whereas approximately 30 genes may cause syndromic RP, such as that seen in Usher syndrome and BBS [2].

Genes that are associated with RP belong to several groups. These include genes encoding proteins that convert a photon into a neuronal signal, a procedure important for normal vision, including rhodopsin $(\mathrm{RHO})$, $P D E 6 A$, and $P D E 6 B$, which encode proteins of the visual cycle that recycle the chromophore of rhodopsin. Other genes encode tetraspanins, are structural photoreceptor proteins; photoreceptor cell transcription factors that enhance the expression of photoreceptor genes, including $N R L$ and $C R X$. Additionally, some genes are involved in the regulation of catabolic functions in the retina, mitochondrial genes that are involved in mitochondrial metabolism, and several other categories. Moreover, there are genes with unknown functions that contribute to the progress of RP, such as $R P 1, R P 2, R P 3$ (RP GTPase regulator, $R P G R$ ), $R P 12$ (CRB1), and $R P 14$ (TULP1) [19].

Hence, most genes encode proteins that are vital for the neuroretina and/or RPE, or some underlying structure. Thus, depending on the gene mutation, impaired or disrupted pathways may be caused. The first gene to be identified in adRP is RHO. Subsequently, several new genes have been implicated in RP pathogenesis. Each of these is associated with a specific RP subtype, which, in turn, is characterized by typical progression, age of onset, symptomatology, and retinal appearance. Several genes, such as CWC27, IMPDH1, and CRX, are related to earlyonset RP, whereas others, such as HGSNAT, CRX, and RBP3 are associated with late-onset RP [7].

A great many mutations in these genes are implicated in RP pathogenesis. There are more than 3100 mutations in non-syndromic RP genes alone $[2,3,6,20]$. Syndromic RP is equally heterogeneous [6] and represents $20-30 \%$ of RP cases [7]. . As mentioned above, mutations in 12-15 genes may be implicated in Usher syndrome pathogenesis and 21 genes with BBS pathogenesis [14]. Another 1200 pathogenic mutations have been implicated in these syndromes. Apart from the genetic heterogeneity that they entail, various overlapping diseases and symptoms may be caused by mutations in the same gene. At the same time, there is great variation in their clinical expression. This variability manifests itself even among patients presenting with the same mutation in the same gene [6]. Within each subtype, various factors play a crucial role, indicating that the RP phenotype may be affected by genetic and environmental factors [7].

To date, approximately 27 adRP, 55 arRP, and 6 xIRP genes have been identified in the Genecards and RetNet databases [1, 11, 14]. Some genes can cause both adRP and arRP, such as RHO, BEST1, NRL, IMPDH1, NR2E3, RP1, and RPE65 [1, 21], while others can cause both RP and macular degeneration (MD), such as ABCA4, PROM1, PRPH2, C8orf37, and PRPF31 [1]. In addition, some genes have been implicated in both RP and LCA (CRB1, RPE65, CRX, LRAT, IMPDH1, PRPH2, SPATA7, RDH12, and TULP1) and others in both RP and cone dystrophy (CD)/CRD (CRX, C8orf37, PRPH2, PROM1, ABCA4, CERKL, SEMA4A, and $R P G R)[2,6]$.

The most prevalent genetic causes of adRP are $R H O$, which causes approximately $26 \%$ of cases, $R P 1$, which causes $6 \%$ 
of cases, and the gene for pre-mRNA processing factor 31, PRPF31, which causes $5 \%$ of adRP in the United States. In Europe, the prevalence is lower for mutations in $\mathrm{RHO}$ (16.5\%) and higher for mutations in PRPF31 (6.7\%) [17]. Other mutated genes associated with adRP are SPP2 (2q37.1), BEST1 (11q12.3), CRX (19q13.32), OR2W3 (1q44), HK1 (10q22.1), TOPORS (9p21.1), GUCA1B (6p21.1), NRL (14q11.2), NR2E3 (15q23), SEMA4A (1q22), FSCN2 (17q25.3), RHO (3q22.1), CA4 (17q23.2), PRPH2 (RDS) (6p21.1), RPE65 (1p31.2), PRPF8 (17p13.3), ROM1 (11q12.3), PRPF31 (19q13.42), IMPDH1 (7q32.1), KLHL7 (7p15.3), RP1 (8q12.1), PRPF4 (9q32), PRPF3 (1q21.2), RDH12 (14q24.1), PRPF6 (20q13.33), RP9 (7p14.3), and SNRNP200 (2q11.2) [12, 20]. It is estimated that among different populations, $50-75 \%$ of RP cases are associated with adRP gene mutations [20]. However, some of these mutations, at a later time, may be proven to be nonpathogenic, whereas other novel mutations that have not yet been identified may be discovered [6]. Table 3 summarizes the genes reported to cause adRP in the current literature.

In contrast, there are approximately 55 genes implicated in arRP. The following cause up to $2-5 \%$ of cases: RPE65 (1p31.2), PDE6A (5q33.1), PDE6B (4p16.3), and RP25. Other genes implicated in arRP are ADIPOR1 (1q32.1), POMGNT1 (1p34.1), ZNF408 (11p11.2), NEUROD1 (2q31.3), IFT172 (2p33.3), IFT140 (16p13.3), HGSNAT (8p11.21), RDH11 (14q24.1), DHX38 (16q22.2), KIZ (20p11.23), BEST1 (11q12.3), ABCA4 (1p22.1), ARL2BP (16p13.3), C2orf71 (2p23.2), C8Oorf37 (8q22.1), CERKL (2q31.3), CLRN1 (3q25.1), CNGA1 (4p12), CNGB1 (16q13), CRB1 (1q31.3), DHDDS (1p36.11), DHX38 (16q22.2), EMC1 (1p36.13), EYS (6q12), FAM161A (2p15), GPR125 (4p15.2), IDH3B (20p13), IMPG2 (3q12.3), KIAA1549 (7q34), KIZ (20p11.23), LRAT (4q32.1), MAK (6p24.2), MERTK (2q13), MVK (12q24.11), NEK2 (1q32.3), NR2E3 (15q23), NRL (14q11.2), PDE6G (17q25.3), PRCD (17q25.1), PROM1 (4p15.32), RBP3 (10q11.22), RGR (10q23.1), RHO (3q22.1), RLBP1 (15q26.1), RP1 (8q12.1), SAG (2q37.1), SLC7A14 (3q26.2), SPATA7 (14q31.3), TTC8 (14q32.11), TULP1 (6p21.31), USH2A (1q41), ZNF513 (2p23.3) [12, 14]. Table 4 summarizes the genes reported to cause arRP in the current literature.

Six gene loci, mapped to the X-chromosome, have been implicated in XIRP pathogenesis: RPGR (Xp11.4), $R P 2$ (Xp11.23), RP6 (Xp21.3-p21.2), OFD1-RP23 (Xp22.2), RP24 (Xq26-q27), and RP34 (Xq28-qter), the product of at least two of which have been identified: RPGR or RP3 and the RP2 protein (RP2) $[6,18]$. It seems that $R P G R$ mutations are responsible for approximately $70-90 \%$ of $x I R P$ cases and more than $20 \%$ of all RP cases, while $6-20 \%$ of $x$ IRP cases are caused by $R P 2$ mutations. In particular, RPGR is thought to be one of the most significant RP genes as it impacts central vision and appears at a high incidence [18]. Although, $30-60 \%$ of all xIRP cases are associated with the ORF15 region, only $20 \%$ of RP3 mutations are present in RPGR coding exons. Thus, more than $80 \%$ of clinical cases are associated with $R P G R$ and $R P 2$. Hence, gene therapy and small-molecule drugs may focus on these genes [12].

Interestingly, although the RP genes are universal, new mutations appear at roughly the same rate worldwide, and there are differences in the prevalence among different populations. For example, $\mathrm{RHO}$ mutations are responsible for $30 \%$ of adRP cases in Americans of European origin, but only $10 \%$ of such cases in China. This is thought to be due to the absence of the Pro23His mutation in China. On the other hand, the prevalence of other gene mutations, such as that of mutations in RPGR, is roughly the same worldwide [20].

\section{Genetic diagnosis of RP}

The functions of many genes have been extensively studied, but there is partial overlap of the clinical phenotypes of a number of these. Thus, it is necessary to discover accurate genotype-phenotype correlations. Two main methods have been used for genetic diagnosis of IRD. Either specific genotyping microarrays are used which, depending on the IRD form, detect $11-70 \%$ of mutations, or Sanger sequencing is used for mutation screening [3].

Several methods have been used to detect diseasecausing mutations, such as deletion detection, linkage mapping, and subclone sequencing of RPGR ORF15 [20]. Given that a precise prognosis of the symptomatology and appropriate genetic counseling are necessary for the correct management of IRDs, the molecular diagnosis of the IRD is of paramount importance. Important information may be provided by the molecular characterization of IRD-affected patients for the potential use of gene therapy. In addition, the development of new technologies, such as next-generation sequencing (NGS), has enabled the analysis of dozens of genes. This technique provides an easier molecular diagnosis of IRD, as it is characterized by high sensitivity and efficiency despite the heterogeneous nature of IRDs. NGS is thought to be very accurate in screening gene mutations and hence may be used efficiently as a diagnostic tool [3]. Three advanced technologies are using NGS, each with advantages and disadvantages: targeted retinal-gene capture NGS, whole-exome NGS, and whole-genome NGS. However, the present limitations of the NGS methods curb 
their ability to detect insertions, deletions, and variablelength repetitive elements [20].

As already mentioned, gene therapy may be used widely in future, based on efficient and accurate diagnosis of the disease and disease-causing mutations. However, RP management may also be based on new approaches for cell replacement. Transplantation of stem cells may provide better vision in patients with RP. In addition, stem cells could restore structures of the retina that are affected in these patients, particularly when used at the appropriate time and stage of the disease. Previous animal studies on the use of stem cells, which can differentiate into retinal cells and progressively develop features of new cells, have shown encouraging results. However, future studies must optimize these approaches for their use in humans [22].

Oxidative stress may also be a causative factor of various retinopathies, including $\mathrm{RP}$, as it may enhance the death of photoreceptor cells. On the other hand, in the early stages, increased intake of lutein, an important antioxidant, may provide satisfactory protection to the retina and the macula, particularly in predisposing individuals. This emphasizes the need for early diagnosis. Similar protection of the retina and photoreceptors has been attributed to anthocyanins [23].

The aim of molecular studies is to facilitate accurate genetic testing in RP patients, to provide information for use in clinical care and counseling. Additionally, new treatments based on improved understanding of disease pathogenesis will be developed. However, to attain this target, close cooperation between retinal specialists, genetic counselors, molecular geneticists, and bioinformatics experts is needed [20].

The extremely high heterogeneity of RP has led to many attempts to analyze and map the genes that contribute to the appearance and progression of several types of RP [6, 12 , 14]. Below, some of the most important genes involved in adRP, arRP, xIRP, and digenic RP are discussed.

\section{SPECIFIC GENES INVOLVED IN RP PAHOGENESIS}

\section{RHO}

RHO (RP4, Opsin-2) is located on chromosome 3q22.1 and encodes the rod-specific protein, rhodopsin, which belongs to the $\mathrm{G}$ protein-coupled receptor (GPCR) family $[6,11,24,25]$. Rhodopsin is produced in the inner segment (IS) of rods and is transported to the outer segment (OS) of the rods. It is a visual pigment that mediates vision in dim light, and it begins the visual transduction cascade [11].

The protein is composed of 348 amino acids, with seven transmembrane domains, a luminal $\mathrm{N}$ terminus, and a cytoplasmic C-terminus. The activation of rhodopsin protein is controlled by the 11-cis-retinal attachment site (Lys296), which is found in the seventh transmembrane domain [11].

RHO is known as the "major" gene of adRP $[2,4,6,24,25]$. It is also defined as RP4 and is responsible for about 20$30 \%$ of all adRP cases. More than 150 mutations in $R H O$ have been identified as causing RP. The first RP causative gene defect in $\mathrm{RHO}$ was p.P23H, which is implicated in approximately $12 \%$ of USA RP patients $[11,19]$.

Additionally, mutations in this gene are responsible for arRP. However, only a few arRP-causing mutations have been identified in $R H O$ [11, 19], which are also associated with adCSNB $[2,6]$. The prevalence of $\mathrm{RHO}$ mutations in adRP has been estimated to range from $16 \%$ to $35 \%$ in Western populations. In the Israeli and Palestinian populations, $\mathrm{RHO}$ mutations are also a significant cause of adRP [26]. Disease-causing mutations have also been identified in Spanish [27], Iranian [28], Japanese 29, and Korean [30] families with adRP. In Swedish families, mutations in $\mathrm{RHO}$ are associated with phenotypic intrafamilial variability and more severe phenotypes in younger generations [17]. For arRP, RHO mutations have been identified most frequently in Chinese families, The p.P347L mutation is the most common RHO mutation in China and is also a significant RP-associated mutation worldwide [11].

Finally, as $R H O$ is a major causative gene in adRP, many therapies targeting $\mathrm{RHO}$ have been attempted in experimental animals. Moreover, the use of genecorrected autologous induced pluripotent stem cells (iPSCs) has been suggested for treating adRP patients [11].

\section{PRPH2/RDS and ROM1}

$P R P H 2$ is located on chromosome $6 \mathrm{p} 21.1$. This gene is also known as retinal degeneration slow/RDS [27]. It contains three exons and encodes peripherin 2, an integral membrane glycoprotein of $39-k D a$, which is composed of 346 amino acid proteins $[2,6]$. This protein contains one intradiscal domain (D2) and four transmembrane domains (M1-M4) [31]. ROM1, which encodes rod outermembrane protein 1, along with RDS, encodes structural proteins of the photoreceptors; hence, it is important for the development and function of rods and cones. These proteins form heterotetramers in rod OS discs. ROM1 and $P R P H 2$ encode proteins of the tetraspanin superfamily, which include four-transmembrane-domain proteins [19]. Tetraspanins, as a family, contribute to the development of several signaling pathways and are associated with many different molecules. However, the heterogeneity of symptomatology in RP patients with either $P R P H 2$ or ROM1 mutations indicates that another interacting protein is probably involved. Prominin like-1 (PROM-1) is 
probably responsible for these interactions. It is a fivetransmembrane-domain protein localized to rod OS discs. PROM1 is mutated in autosomal recessive retinal degeneration [19].

$P R P H 2$ is thought to be a significant causative gene of adRP and CRD [27, 32-34]. Disease-causing mutations in $P R P H 2$ are related to both adRP and adMD [1, 6, 35]. $P R P H 2$ may be responsible for adSTGD1-like phenotypes [36], whereas a few dominant adult onset vitelliform macular dystrophy (AVMD) patients also carry mutations in PRPH2 [2, 37, 38]. It may also be related to secondary defects in neighboring tissues, including the choroid and RPE [31]. Thus, mutations in PRPH2 may be a direct cause of RP [19]. Over 151 PRPH2 mutations have been identified, many of which have been confirmed to be pathogenic. However, PRPH2-associated disease phenotypes display substantial variability, even among blood relatives carrying the same mutation [31].

Mutations in $R O M 1$ are not clearly linked to monogenic adRP [31]. However, an uncommon form of RP is autosomal digenic RP, which involves heterozygous mutations in both ROM1 and PRPH2 [2, 6, 39]. However, cases have been reported where RP is caused by ROM1 mutations in the absence of $P R P H 2$ mutations, whereas PRPH2 mutations have also been reported in several macular pattern dystrophies [19]. The question that has been pursued is how different mutations give rise to differences in disease phenotypes [40-42], but as of yet, this remains unclear. Many of the genes associated with retinal disease can potentially modify $P R P H 2$-associated phenotypes. Among them, ROM1 is the most widely explored gene, due to the existence of PRPH2/ROM1 digenic RP and ROM1 interaction with PRPH2. However, other genes have also been implicated in modifying the PRPH2-associated MD phenotype, including ABCA4 [31].

The prevalence of adRP-related $P R P H 2$ mutations varies widely according to the populations studied, ranging from $0 \%$ in Mexican populations to $10.3 \%$ in French populations $[24,43]$. PRPH2 is the second most common cause of adRP after $R H O$, in the French population. Moreover, $P R P H 2$ mutations were found in $4.7 \%$ of a Belgian cohort. $P R P H 2$ mutations are associated with highly variable phenotypes. These include moderate and mild forms of adRP. Mild forms can, at times, be underdiagnosed [43]. Most PRPH2 mutations are sequence variants. Aberrant mRNA splicing, problems in protein localization, and protein degradation are some of the mechanisms which may result in decreased PRPH2 protein expression in rod OS [24].

PRPF3, PRPF4, PRPF6, PRPF8, PRPF31, and SNRNP200 PRPF3, PRPF4, PRPF6, PRPF8, and PRPF31 encode pre-RNA processing factors $3,4,6,8$, and 31 , respectively [2]. Of these, PRPF3, PRPF8, and PRPF31, together with $S N R N P 200$, are the major causative genes of RP. Indeed, the U4/U6-U5 tri-snRNP complex is composed of PRPF3, PRPF8, PRPF31, and SNRNP200 and is a major component of the spliceosome that participates in mRNA splicing [4, 27, 44, 45]. More specifically, SNRNP200 encodes helicase hBrr2, a 200-KDa protein. Helicase hBrr2, together with several other RNA helicases, mediates the structural rearrangement of the spliceosome, permitting the unwinding of the U4/U6 snRNP duplex, and activating the catalytic properties of the spliceosome complex [4]. Both heterozygous and homozygous variants of this gene cause RP [46]. Approximately $38 \%$ of adRP patients showed mutations mainly in SNRNP200 and PRPF8 [4]. PRPF4 and PRPF6 mutations also cause adRP, albeit less frequently. All tissues in all eukaryotes express PRPF4 and PRPF6 [2]. PRPF4 encodes HPrp4, which is essential for continuous splicing. It has been reported that this gene co-segregates with the adRP disease phenotype in a Chinese family [47]. PRPF31 is located on 19q13.42 [2]. It is composed of 14 exons and encodes a 499-amino acid protein that is implicated in spliceosome function. It binds to U4 small nuclear ribonucleoprotein (snRNP) in U4/U6 di-snRNP and contributes to the development of a connection between U5 and U4/U6 di-snRNP. PRPF31 is a common causative gene of adRP, after RHO and PRPH2, with over 40 RPcausing mutations identified to date [48]. Furthermore, PRPF31 mutations have been reported to cause both RP and $M D$ [1]. According to study on affected family with adRP in a large Chinese family, the age of RP patients ranged from 22 to 71 years, although the onset of night blindness extended from infancy to the fourth year of life [48].

The phenotype of PRPF31 disease-causing mutations is highly heterogeneous, with extreme inter- and intrafamilial variability [17, 34]. Although these mutations cause adRP, they are non-penetrant, and several mutations are present without clinical manifestation [4850]. As a result, a few carriers of these mutations are blind, whereas others are asymptomatic [51]. Genetic modifiers are a potential cause of phenotypic variability. CNOT3 encodes a protein of the CCR4-NOT complex, which is a conserved multiprotein structure that regulates gene expression. It is also a modifier in PRPF31-associated adRP, which explains the incomplete penetrance observed in families segregating these mutations [17]. In adRP, the prevalence rate of PRPF31 mutations in different populations varies from $1 \%$ to $8 \%$ [52]. In the United States, this frequency is approximately $5 \%$. In Europe, the prevalence is higher $(6.7 \%)$ than in the American population. PRPF31 mutations have also been 
reported in a Swedish population [17]. The prevalence of PRPF31 mutations in the Spanish population is estimated to be $7.6 \%$, which is similar to that found in a French population (6.7\%) [53]. However, these mutations are extremely rare in Asian population-based databases [29]. The prevalence of mutations in PRPF8, PRPF31 and SNRNP200, is high (19.8\%) in the Belgian population. Mutations in PRPF31 have a prevalence of $10.5 \%$ ( $53 \%$ of the $19.8 \%$ ). Together, mutations in PRPF8, PRPF31, and SNRNP200 are the major causative genes of adRP in the Belgian population [24].

In addition, PRPF3 (RP 18, SNRNP90) contains the three main mutations associated with ethnic variability in RP. The mutation T494M, the most frequent substitution in this gene, is a common causative mutation in adRP. T494M has been detected in American, Danish, English, Spanish, Swiss, Korean, and Japanese adRP families. P493S was identified in sporadic RP cases from Germany or the UK, as well as in a Caucasian adRP family in the USA. A489D has been referred to as an adRP family in Spain. On the other hand, PRPF3 mutations are rare in Chinese adRP patients [44].

\section{RP1}

$R P 1$ is located on $8 q 12$ chromosome and contains four exons. It encodes a 2,156 amino acid protein, oxygenregulated protein $1[21,54,55]$. It is localized at the connecting cilia of rods and cones [55] and contributes to photoreceptor development, organization of photoreceptor OSs, and regulation of photoreceptor microtubules [54, 55]. Disease-causing mutations in this gene may cause both adRP and $\operatorname{arRP}[1,3,15,24,56]$, often associated with a relatively good prognosis [54]. In 1999, it was thought to be an adRP-causing gene, but later arRP cases were associated with RP1 mutations. According to the estimate, disease-causing mutations in this gene account for $5 \%$ and $1 \%$ of adRP and arRP cases, respectively [55]. In addition to adRP and arRP, some studies have provided evidence that arCRD and arMD are also RP1-associated phenotypes [57].

To date, over 150 disease-causing mutations have been detected in RP1, most of which are truncation variants. However, the pathway responsible for the dominant/recessive mutation effect remains unknown. It has been reported that deleterious effects of the truncated RP1 protein, caused by RP1 nonsense mutations, are mostly implicated in the development of retinal degeneration. In addition, it has been proposed that there are four distinct categories of truncation mutations in RP1 that affect the progression of RP differently [55].
Incomplete penetrance and variable expressivity have been observed in individuals carrying RP1 mutations, resulting in phenotypic variability, including the age of onset, abnormalities of the central and mid-peripheral retina, visual acuity and visual fields, and ERG findings. RP patients with homozygous or heterozygous RP1 mutations may develop arRP, which progresses in childhood, presenting with night blindness and progressive loss of visual acuity until the twentieth year of life. However, RP1 mutation carriers mostly appear asymptomatic, whereas an increased risk of hypertriglyceridemia has been reported in homozygous carriers of p.N985Y [54].

A nonsense mutation at codon 677 (p.R677) was one of the first analyzed RP1 mutations, which was estimated to be present in approximately $3 \%$ of adRP patients in North America [21]. Disease-causing mutations have also been identified in Iranian [28], Japanese [29] Korean [30], and Spanish families [27] with adRP, whereas disease-causing mutations were also identified in Spanish patients with $\operatorname{arRP}[55]$.

\section{CRX}

$C R X$ is localized on chromosome 19q13.33. It contains four exons and encodes a protein of 299 amino acids that is a homeodomain transcription factor $[2,6,58]$. $C R X$ and $N R L$ are photoreceptor cell transcription factors that control the expression of photoreceptor cell-specific genes, and both are known be mutated in the RP. Those mutations may prevent the development of rods and cones, and may cause degeneration of these cells over time [19]. Mutations in $C R X$ can also lead to recessive, dominant, and de novo LCA, adCRD $[2,6,19]$, and $\operatorname{adRP}[33,35,58]$. ArRP-causing mutations in $C R X$ have been reported in Japanese and other populations [29]. The phenotype of $C R X$ mutations is heterogeneous, and incomplete penetrance of the mutations may be related to the influence of other genes $[59,60]$.

$C R X$ is also a common CRD-causative gene [32, 33, 60], and missense changes are most frequently found in adRPassociated genes [27]. CRX mutations, like GUCY2D, AIPL1, and RPGRIP1 mutations result in poor visual acuity, starting within the first year of life [61]. In addition, $C R X$ mutations associated with LCA often involve hyperopia [7].

\section{RPE65}

RPE65 is located on 1p31.2, and encodes a 65-kDa retinol isomerase called RPE-specific protein that contributes to the visual cycle by renewing 11-cis retinal from all-trans retinol $[2,6,62]$. It is a member of the carotenoid cleavage oxygenase (CCO) enzyme family [61, 63, 64].

More than 100 mutations in RPE65 have been associated with $\operatorname{arLCA}[2,6,35,62,65,66], \operatorname{RP}[6,35,62,65]$, and CRD 
[67]. Additionally, a potential association with AVMD has been described [64]. More specifically, RPE65 mutations can cause both adRP and arRP $[1,6]$, but most mutations are associated with arRP [62].

RPE65-associated adRP also affects the choroid [63]. RPE65 mutations cause severe retinal dystrophies, mainly due to protein dysfunction and recessive inheritance. The c.1430A>G:p.Asp477Gly (D477G) mutation is the only known exception to this rule to date, as it is the cause of delayed-onset adRP and also affects the choroid and the macula [62]. Various phenotypes are present in D477G mutation carriers, including differences in the age of disease onset and disease severity, while most of them initially present with central visual impairment. They differ from typical RP patients, who present with progressive visual field loss starting from the mid-region and progressing to the far periphery $[63,64]$.

Patients with disease-causing mutations in RPE65 present early-onset degeneration, keratoconus, nystagmus, white dot deposits, and clumped pigment in advanced disease [68]. Severe visual impairment and night blindness are observed during infancy, and photophobia is observed during childhood [69]. High hyperopia is an additional common feature [67]. RPE65 mutations are also responsible for progressive visual impairment in older individuals. In addition, the appearance of symptomatology after infancy has been associated with better prognosis [61].

The highest prevalence of RPE65 variants is encountered in Caucasian populations, while high frequencies (16.5\%) of RPE65 variants have been reported in the Indian population [70]. RPE65 mutations are responsible for approximately $16 \%$ of LCA cases, although it seems that this gene is not involved in Chinese LCA cases [67, 71]. On the other hand, adRP cases caused by RPE65 have been identified among Irish families, and is thought to reflect an Irish founder mutation $[62,64]$.

\section{ABCA4}

$A B C A 4$ consists of 50 exons and is located on chromosome $1 \mathrm{p} 13$ [72]. The encoded protein is an ATP-binding cassette $(A B C)$ transporter protein localized to the rims of rod and cone discs $[6,72-75]$. The main function of the ABCA4 protein is to transfer both $\mathrm{N}$-retinylidenephosphatidylethanolamine and phosphatidylethanolamine from OS disc membranes of photoreceptors to the cytoplasmic leaflet during phototransduction. Thus, ABCA4 eliminates potentially toxic retinoid compounds from photoreceptors [72, 74, 75].

At present, more than 800 mutations have been linked to $A B C A 4$-associated phenotypes. ABCA4 mutations may be simple single-base substitutions or may be as extensive as the deletion of a few exons. However, most are missense mutations [72]. The severity of the retinal dystrophy phenotype may be related to the degree of mutation pathogenicity, which depends on their localization in various regulatory regions of the gene and the effect of the mutation on the amino acid composition of the protein molecule [76].

$A B C A 4$ mutations are heterogeneous and are the most common cause of central retinal dystrophies [30, 33]. They can cause autosomal recessive Stargardt disease (arSTGD1), CD, CRD, and arRP [75-79]. In fact, ABCA4 is the major causative gene of STGD [36], and are commonly responsible for arCRD. ABCA4 has been reported as a major contributing gene to arCRD, whereas other known arCRD-related genes, including PROM1, accounts for only a minor fraction of the reported cases [80].

Some studies have also indicated that $A B C A 4$ mutations are associated with atypical Usher syndrome $[3,81]$. The most severe arRP phenotype involves injury to both the rods and cones. To date, 27 missense/nonsense mutations, nine splicing mutations, four deletions, and a complex rearrangement are thought to be responsible for homozygous or compound heterozygous arRP [82].

Additionally, disease-causing mutations in $A B C A 4$ are extremely heterogeneous with respect to ethnicity. In European patients, the p.G1961E mutation is prevalent at a frequency of $20.5 \%$. On the other hand, p.A1773V and p.G818E are present in $17 \%$ and $15 \%$ of Mexican patients, respectively [77]. Among Thai patients, ABCA4 mutations are mainly responsible for the RP phenotype [6], whereas they are very rare in Chinese and Polish patients with $\operatorname{arCRD}[73,83]$. However, their frequency ranges from $16.13 \%$ to $65 \%$ in European and American patients [73].

Electrophysiology contributes significantly to the diagnosis and follow-up of $A B C A 4$-associated retinal disorders. Different phenotypeswere identified using different ERG patterns. In STGD, multifocal ERG (mERG) is typically attenuated with ffERG remaining normal or slightly affected. In CRD, mERG is always significantly attenuated, as are the cone responses in ffERG. ArRP is associated with an initial attenuation of the ffERG rod response, followed by reduced cone responses [84, 85].

\section{CRB1}

CRB1 encodes two proteins (1,376 and 1,406 amino acids long). It contains 12 exons and 11 introns and is located on $1 q 31.3[6,86]$, The CRB1 protein is an extracellular signal protein. CRB1 includes three laminin A globular (AG)-like, a C-type lectin (CTL), and 19 epidermal growth factor (EGF)-like domains, and is extremely important for the formation and function of the retina [40, 86-88]. 
To date, more than 200 CRB1 mutations implicated in arRP pathogenesis have been identified [40]. Among patients with RP attributable to CRB1 mutations, severe forms of retinal degeneration, such as LCA, appear in patients with null mutations in both alleles, including nonsense and frameshift mutations, whereas less aggressive forms, such as RP, are produced by heterozygous missense mutations $[88,89]$. CRB1 mutations that lead to RP are associated with night blindness, followed by progressive peripheral vision loss, rod and cone degeneration, and rarely associated with complete blindness [88]. Disease-causing mutations in CRB1 frequently cause hyperopia [7]. CRB1 mutations are related to various phenotypes and retinal dystrophies, such as early-onset RP, LCA, and CRD, and central phenotypes, including $\mathrm{MD}$ and foveal retinoschisis [6, 33, 35, 40, 61, 82, 86, 88, 90-92].

In addition, CRB1 mutations are responsible for 3-9\% of non-syndromic arRP cases [91]. Moreover, it was observed that 9-15\% of LCA cases have mutations in CRB1 [93]. Recessive CRB1 mutations may also cause CRD with $M D$ in childhood, with electronegative ERG [94]. These mutations are also responsible for adSTGD1-like phenotypes [36]. The variability of clinical manifestations in arRP patients with the same mutation in CRB1 indicates that other unknown factors may affect the pathogenesis [95].

CRB1 mutations frequently cause autosomal recessive retinal degeneration of early-onset in individuals from Israel, Palestine, and Spain [40, 89]. CRB1 mutations have been reported in four Chinese families. CRB1 sporadic mutations have been reported in RP subjects at a frequency of $5.8 \%[40,92]$. The most common types of arRP-causing mutations in patients from Israel and Palestine are also localized in CRB1. Furthermore, they are also present in Thai families with non-syndromic RP [96]. CRB1 mutations are also the most frequent cause of LCA among German patients [97]. Moreover, the prevalence of CRB1 mutations in a Danish LCA cohort was estimated at 7\% [70]. CRB1 mutations have also been reported in the Brazilian CRD population [86]. In addition, it has been reported that Tunisian families with RP present mutations in CRB1, which are characterized by preserved paraarteriolar RPE [68].

\section{PROM1}

PROM1 is located at $4 \mathrm{p} 15.32[6,39,98]$ and consists of 27 exons. It encodes prominin-1, a five-transmembranedomain glycoprotein $[6,39,84,98]$. The gene contributes to the development of disk membranes and is localized at the OS base of rods and cones. Stem and progenitor cells of several systems, such as neural and hematopoietic cells, or epithelial, glial, and photoreceptor cells of various organs, express the protein [98].

Thirty-five PROM1 mutations have been identified [39]. The different disease-causing mutations in PROM1 have been suggested to be related to a variety of retinal degenerative phenotypes, such as arRP with MD, adSTGD1-like MD, autosomal dominant bull's-eye MD, and CRD $[1,84,99]$. It has been reported that each PROM1 mutation is related to a different phenotype. Missense mutations are mostly related to adSTGD1-like or bull's-eye MD. On the other hand, diseases such as RP and severe CRD with MD and nyctalopia are caused by nonsense and frameshift mutations in this gene [39, 83, 100].

Moreover, PROM1 mutations are strongly related to adCRD or $\operatorname{arCRD}[30,32,33,80,98]$ and adSTGD1-like phenotypes [30, 34, 84, 101, 102] In addition, carriers of PROM1 mutations have clinical manifestations of adMD [99]. PROM1 mutations are associated with high myopia [100], while the first symptoms of RP patients with PROM1 mutations are nyctalopia and loss of visual fields [98].

In Thai and Chinese families, mutations in PROM1 are often responsible for arRP $[39,96]$. In addition, recessive PROM1 mutations have been implicated in a Spanish family presenting with severe RP accompanied by MD and myopia. In these cases, PROM1 dysfunction may cause retinal degeneration [100].

\section{PDE6}

Mutations in the gene encoding cyclic guanosine monophosphate (cGMP) phosphodiesterase 6 (PDE6) are responsible for approximately $8 \%$ of arRP cases. Abnormal cGMP metabolism may affect the visual signaling pathway, resulting in the death of photoreceptors and retinal degeneration. Hence, the regulation of cGMP concentrations in rods and cones is thought to be vital. Dysfunction of PDE6 may lead to photoreceptor degeneration, although the mechanisms initiating rod photoreceptor death are unclear [14].

The PDE6 complex (including its PDE6A, PDE6B, PDE6G subunits) is crucial for rod phototransduction. Little is known about the processes that induce rod photoreceptor death in RP; however, low PDE6 activity apparently results in rod-cone devolution. All PDE6 subunits are necessary for proper photoreceptor function. PDE6A and PDE6B mutations seem to, quite commonly, induce arRP and heterozygous carriers of mutations in PDE6 are thought to be at a significant risk of visual loss. In contrast, PDE6G mutations are likely to cause earlyonset arRP [14].

In particular, the PDE6B, located on $4 \mathrm{p} 16.3$, encodes the rod CGMP phosphodiesterase beta subunit. $P D E 6 B$ mutations are related to $\operatorname{arRP}[6,103,104]$, and they have 
been identified in specific ethnic groups $[30,68,105]$. In the Korean population and in Caucasian Jews, PDE6B mutations are an extremely common cause of arRP [30, 105]. RP caused by PDE6B mutations is characterized by childhood onset, night blindness, and photophobia [79, 103], Mutations in PDE6B are also responsible for adCSNB [6].

\section{TULP1}

TULP1, located on 6p21.31, is expressed only by rods and cones, and encodes the 542-amino acid tubby-like protein 1 , a member of the homonymous protein family $[6,106$, 107]. It consists of 15 exons in a 15-kb region. Rhodopsin, which is synthesized in the ISs of rods, is transported by TULP1 to the OSs via the connecting cilium (CC) $[107,108]$. TULP1 is one of nine genes that have been implicated in the pathogenesis of both RP and LCA (RPE65, CRB1, SPATA7, CRX, RDH12, LRAT, TULP1, IMPDH1, and PRPH2) [35]. Disease-causing mutations in TULP1 have been reported in juvenile-onset arRP, rod-cone dystrophy (RCD), and arLCA, implicating this gene with retinal degeneration [6, 15, 35, 61, 106-108]. Mutations in this gene have also been reported in Thai families with arRP and arLCA [96].

There is clinical and genetic overlap between (early-onset) arRP and LCA, and it is often very difficult to differentiate these two conditions [107]. Biallelic TULP1 variants are associated with nystagmus, progressive nyctalopia, myopia, abnormal ERG, normal visual acuity and visual field in the first decade of life, and abnormalities of the peripheral retina [106, 108, 109]. In particular, nystagmus appears to be an unstable clinical feature [109].

\section{C8orf37}

C8orf37, a gene located on 8q22.1 [6], encodes a 207amino acid protein of approximately $23 \mathrm{kDa}$ whose function has not been determined. The C8orf37 protein colocalizes with $\gamma$-tubulin in immunolocalization studies of the retina, which is a basal body marker at the $\mathrm{CC}$ of rods and cones [41]. Therefore, mutations in C8orf37 may hinder intracellular traffic and thus play a role in the pathophysiology of RP, CRD, and BBS $[1,15,110]$. C8orf37 mutations cause arRP and $\operatorname{arCRD}[6,15,110,111]$. However, C8orf37 mutations are implicated in the pathogenesis of some BBS (BBS21) cases [110]. The relationship between C8orf37 mutations and BBS (BBS21) suggests that $C 80 r f 37$ mutation carriers should be under surveillance to prevent the potential development of BBScontributing morbidities, such as obesity, renal abnormalities, diabetes, and hypertension [110, 111]. The phenotypic heterogeneity associated with C8orf37 mutations is wide, and overlap between RP and CRD is common. Distinguishing between RP (nyctalopia and developing visual field constriction) and CRD (photophobia, loss of central vision) greatly depends on their early symptoms. Given the substantial phenotypic overlap at the early stages, it is difficult to make a differential diagnosis of these conditions in their most severe presentations [41].

C8orf37 is also reported to be a causative gene of arRP in Thai families [96]. In addition, C8orf37 mutations have been reported to cause RP in two families from Pakistan. However, they are thought to be a rare cause of retinal dystrophy in this population [41].

\section{RPGR}

$R P G R$, located on Xp11.4 [6, 112], RP2, and OFD1 are genes associated with $\mathrm{xIRP}[10,113]$. Mutations in $R P G R$ are responsible for approximately $70-90 \%$ of xIRP cases and mutations in RP2 cause around $6-20 \%$ of xIRP cases $[10,114]$. There are more than 10 alternatively spliced transcripts of $R P G R$, while RPGRconst and $R P G R^{\mathrm{ORF} 15}$ are the two major RPGR isoforms identified $[10,114]$. The phenotypic spectrum of $R P G R$ mutations is highly heterogeneous [42]. Mutations in $R P G R^{\mathrm{ORF} 15}$ may provoke xIRP, X-linked MD (xIMD), X-linked CD (xICD), and X-linked atrophic MD [6, 10, 33, 73, 112, 114]. Approximately 50$60 \%$ of RPGR mutations are clustered in the ORF15 exon, indicating that it is a hotspot for mutations. Most of these mutations are frameshift mutations, because the purinerich structure of the ORF15 exon apparently promotes polymerase arrest and slipped-strand mispairing events. Truncated products of RPGR ${ }^{\mathrm{ORF} 15}$ of different lengths, affecting RPGR ${ }^{\mathrm{ORF} 15}$ glutamylation, are caused by frameshift mutations [10, 114]. In addition, impaired glutamylation of RPGR ${ }^{\mathrm{ORF} 15}$ is triggered by TTLL5 disease mutations, causing retinal dystrophy. Hence, in the absence of RPGR ${ }^{\mathrm{ORF} 15}$ glutamylation, patients with TTLL5 mutations present with retinal pathology because these two genes are components of a common disease pathway [18].

A large deletion in $R P 2$ and four frameshift $R P G R$ mutations have been identified in five families from China affected by xIRP [10]. Mutations in these genes have also been detected in Jordanian families with this disease [113]. Furthermore, disease-causing mutations have been identified in Japanese and other populations [29].

Mutations in RPGR cause LCA and juvenile RP. However, cases have been reported where the disease course was benign, with good visual acuity at presentation, which remained fairly stable up to over 40 years of age [34]. Nyctalopia and vision decline are present in RP-affected males with RP2 mutations. Males present with a graver phenotype than carrier females, who show different degrees of severity of myopia. With RP3 mutations, males 
present with more severe phenotypes, while carrier females have several different clinical manifestations, from asymptomatic to severe RP. In addition, most of the females present with reduced vision, but rarely progress to complete blindness [112].

The genotypic spectrum of RPGR variants has also been associated with systemic manifestations. The identification of these features in males and the phenotype in carrier females allows confirmation of pathogenic variants [115]. In addition, blindness by the age of 40 years occurs in approximately $20 \%$ and $55 \%$ of $\mathrm{RP}$ and CD/CRD patients, respectively [116].

\section{USH2A}

USH2A is located on chromosome 1q41 [6]. It consists of 72 exons and encodes usherin, a 5,202 amino acid protein. This protein is localized at the apical IS recess of rods and cones of mammals, corresponding to the periciliary ridge complex that appears in the rods and cones of amphibia [117].

It is estimated that $10-15 \%$ of arRP cases and $30-40 \%$ of Usher syndrome type 2 cases are associated with USH2A mutations [117]. Moreover, mutations in USH2A, RPGR, $P R P F 31$, and EYS are implicated in $48 \%$ of RP cases with known mutations [34]. Because USH2A mutations may be responsible for non-syndromic RP and Usher syndrome, their presence in a family necessitates a hearing examination for these patients [3]. In addition, late-onset non-syndromic arRP may be associated with USH2A mutations [79].

Approximately $7 \%$ of RP cases in the USA are associated with mutations in USH2A. In addition, USHA2 mutations causing arRP have a high prevalence and show phenotypic variations among Spanish RP patients [117]. Approximately $74-90 \%$ of Usher syndrome 2 cases in Caucasians are related to USH2A, which is also thought to be a significant causative arRP gene. Among Japanese patients with arRP, the prevalence of these mutations is $4 \%$. However, the Japanese and Caucasian population profiles of these mutations differ [118]. In addition, EYS and $U S H 2 A$ are thought to be the major genes responsible for RP in Japan $[29,119]$. Furthermore, there are specific USH2A mutations associated with RP, without hearing, loss among Chinese and Thai patients [96, 120]. Finally, USH2A seems to be important in the pathogenesis of the disease among Israeli IRD cohorts [81] and arRP Korean families [30].

\section{RDH12}

$R D H 12$ is located on $14 q 24.1$, and encodes an NADPHdependent retinal reductase that is a member of the retinol dehydrogenase family. $R D H 12$ plays a vital role in the conversion of all-trans retinal and 11-cis retinal to their respective retinols. The protein is expressed in the ISs of rods and cones and plays a vital role in the cyclic regeneration of the 11 -cis retinal and cone opsins $[2,6$, 61].

RDH12 mutations, which account for $3-7 \%$ of all ar retinal dystrophy cases, are significant causative genes of LCA [2, $6,35,61,65,90]$. Over 60 RDH12 mutations have been reported, mainly in patients with LCA and in early-onset retinal dystrophy cases occurring in families with arRP. Based on this, $R D H 12$ mutations may cause many severe forms of blindness [61].

RP RDH12 mutations are commonly associated with juvenile RP [68]. Late-onset and mild adRP may be caused by heterozygous $R D H 12$ mutations $[61,99]$. Retina-wide disease, of early-onset, accompanied by abnormalities particularly in the central retina, may be caused by $\mathrm{RDH} 12$ mutations. This disease, with less rod dysfunction, has many similarities to early-onset CRD [121].

\section{BEST1}

BEST1, which is localized on 11q12-13, consists of 11 exons and encodes a protein named bestrophin-1 [2, 122]. It is expressed predominantly in RPE and is a $\mathrm{Ca}^{2+}$ activated $\mathrm{Cl}^{-}$channel. It is an inhibitor of the intracellular voltage-dependent $\mathrm{Ca}^{2+}$ channel and $\mathrm{HCO}_{3}{ }^{-}$transporter [122, 123].

More than 300 BEST1 mutations have been identified. They cause bestrophinopathies, such as BEST vitelliform MD (BVMD) and autosomal recessive bestrophinopathy (arB). Patients with BVMD and arBs present with wide genetic and phenotypic variability [123].

Furthermore, BEST1 mutations are associated with adRP and arRP [1, 124], LCA [123], AVMD, and adSTGD1-like phenotypes [36]. BEST1 is considered to be the major causative gene of vitelliform MD (VMD), even though many of these patients have mutations in genes such as IMPG1/IMPG2, but not in BEST1 or PRPH2 [37].

\section{SPATA7}

SPATA7 is localized on chromosome $14 q 313$ and encodes a spermatogenesis-associated protein 7 [6]. The SPATA7 protein, as a ciliary protein, is located at the primary cilium of cells and at the CC of rods and cones [125].

Mutations in SPATA7 lead to both arRP and arLCA [6, 35, 90]. Furthermore, SPATA7 binds to the RP GTPase regulator interacting protein 1 (RPGRIP1), a CC protein that is related to LCA. The apoptosis of rods, which is caused by protein mislocalization, is probably implicated in the development of LCA and juvenile RP [125].

Patients with SPATA7 mutations show disc pallor, arteriolar thinning, and RPE mottling [90]. There are indications that SPATA7 mutations account for a 
significant number of LCA cases in the Chinese population (4.6\% of LCA patients) [125].

\section{NR2E3}

NR2E3, located on $15 q 23$, encodes the nuclear receptor subfamily 2 group E3 [2]. Two domains are included in NR2E3, the DNA-binding domain (DBD) and the ligandbinding domain (LBD), at the $\mathrm{N}$ - and C-terminus end, respectively. These domains are the NR2E3 regions most commonly mutated [126].

Mutations in NR2E3 are responsible for arRP and dominant and recessive retinopathy. Other diseases, including recessive Goldmann-Favre syndrome and recessive enhanced S-cone syndrome (ESC), may also be caused $[2,19]$. Mutations in this gene can also lead to adRP [1]. Diagnosis is complicated by the presentation of various clinical manifestations and the severity of retinal degeneration caused by these mutations. Patients with NR2E3 mutations may present with Goldmann-Favre syndrome (GFS) features, typical ERG pattern of ESCs, or clumped pigmentary retinal degeneration [126]. In addition, RP disease-causing mutations in NR2E3 are frequently associated with hyperopia [7].

Significant pathogenic mutations have been reported in various populations, including Thai patients [96], Tunisian families [68], and Indian arRP cases [109].

\section{TTC8}

TTC8, located on 14q32.11, encodes tetratricopeptiderepeat-domain 8 and is associated with arRP and recessive BBS [6]. A premature stop codon located in exon 6 of the gene may be triggered by a frameshift mutation in the previous exon. The frameshift mutation in exon 5 also results in the production of TTC8 that lacks the normal tetratricopeptide-repeats 11 and 15. Nonsense and frameshift mutations may reduce translation of the encoded protein. As a result, compound heterozygous patients lack a functional TTC8 protein, a condition that results in the development of BBS type 8. TTC8 mutations are found in only $2.8 \%$ of all patients with BSS. More specifically, in Japan, one family each with BBS2, BBS5, and $B B S 7$ homozygotes have been reported, along with a family with $B B S 10$ compound heterozygotes. However, BBS patients with TTC8 mutations are extremely rare [127].

\section{CEP290}

Heterozygous CEP290 mutations are associated with LCA, early-onset RP [89], and syndromic RP, as it is associated with BBS type 14 [14]. Mutations in this gene are responsible for LCA. The protein is localized in the CC of rods and cones and in the centromeres of diving cells. CEP290 mutations may cause a reduction in OS length and thickness of several retinal layers. Poor visual acuity and rod-cone vision loss were observed in these patients [128]. Sequence analysis in a Danish LCA cohort indicated that CEP290 mutations were responsible for approximately $7 \%$ of the cases [70].

\section{CERKL}

CERKL, located on 2q31.3 [6], encodes a ceramide-kinaselike protein and is associated with arRP $[3,79]$ and CRD. Mutations in the gene may provoke bone-spicule pigmentation with white dots, RPE atrophy in the macular area, chorioretinal atrophy in the central retina, and decreased visual acuity [79].

\section{CNGA3}

CNGA3 encodes the functional components of the phototransduction cascade in cone photoreceptors [129]. Several CNGA3 mutations have been implicated in the pathogenesis of various diseases, including IRDs, and more specifically with autosomal recessive achromatopsia, complete or incomplete achromatopsia, CD or CRD, LCA, and RP [66, 130-133]. CNGA3 mutations have been identified in the Korean population [30] and in Israeli families [81] as a significant cause of IRDs. In addition, mutations in this gene seem to be significant among Chinese patients with CRD and achromatopsia. Hence, many cases of severe retinal dystrophies of earlyonset may be related to CNGA3 mutations [134].

\section{SLC7A14}

Disease-causing mutations in the SLC7A14 cationic transporter gene are responsible for arRP and LCA [135]. SLC7A14 is thought to be an important causative gene for $\mathrm{RP}$ in Japanese patients with arRP or sporadic RP. The frequency and pathogenicity of SLC7A14 mutations may differ in terms of ethnicity, and these mutations were unlikely in Japanese patients [136].

\section{MERTK}

MERTK, a member of the MER/AXL/TYRO3 receptor kinase family, is composed of 19 exons [137] and encodes a 999 amino acid transmembrane protein [66, 137]. Several cells and tissues express this protein, including macrophages, $\mathrm{RPE}$, prostate, lung, and kidney [137].

Approximately $1 \%$ of autosomal recessive retinal dystrophy cases are associated with mutations in MERTK. Progressive retinal dystrophies with childhood onset and macular defects characterize these patients [137]. MERTK mutations cause approximately $2 \%$ of severe IRD cases, including RP and CRD [138]. All known mutations are lossof-function mutations [139]. Patients present with increased sensitivity to light and with dark adaptation problems [33]. Germline MERTK mutations related to arRP have been identified in the Chinese population [139]. 


\section{IMPDH1}

Inosine monophosphate dehydrogenase 1 is the protein product of IMPDH1, which is located on 7q32.1 [2,6]. This protein is involved in purine or amino acid synthesis [2]. Disease-causing mutations in IMPDH1 lead to adLCA and $\operatorname{adRP}[2,6,7,35]$.

\section{SEMA4A}

SEMA4A, located on 1q22 chromosome, encodes semaphorin $4 \mathrm{~A}$ and is associated with adRP and adCRD [2, 6]. SEMA4A mutations are one of the most common causes of CRD [32].

\section{LRAT}

LRAT, located on 4q32.1 chromosome, encodes lecithin retinol acyltransferase, and mutations in this gene are responsible for both arRP and arLCA $[6,35]$. In specific populations, such as the Danish population, LRAT is a significant causative gene of LCA [70]. Disease-causing mutations in LRAT frequently also cause hyperopia in RP patients [7]. Table 5 summarizes the overlap between genes causing RP and causing other IRDs, and Table 6 summarizes all abbreviations used in the text.

This review, in addition to its strengths, has several limitations. The present review focused on articles published in the last decade by using two of the known databases, PubMed and Google Scholar; however, other databases were not searched. It also focused most on important genes that are implicated in RP pathogenesis, while other rare pathogenic mutations in less significant genes were not included. The review is concisely referred to some types of management that may be developed and used in the future, including antioxidant ingredients, stem cells, and gene therapy, without emphasis. Future research should focus on the individual types of $\mathrm{RP}$, and particularly the progression and clinical manifestations caused by specific variants in order to identify more pathogenic mutations from other less aggressive mutations. This may enhance the effort to achieve specialized management, such as promising gene therapy, for each disease-causing mutation.

Table 3. Genes reported to cause autosomal dominant retinitis pigmentosa.

\begin{tabular}{|c|c|c|}
\hline GENE & CHROMOSOME & OTHER DISEASES \\
\hline BEST1 (Bestrophin 1) & $11 q 12.3$ & $\begin{array}{l}\text { Dominant Vitreoretinochoroidopathy }[12,32], \text { Recessive Bestrophinopathy }[12,118 \text {, } \\
\text { 119], Recessive RP }[12,18], \text { Dominant MD [32], Best type }[12,119]\end{array}$ \\
\hline CRX (Cone-Rod Homeobox) & $19 q 13.32$ & Recessive, Dominant and de novo LCA $[2,6]$, Dominant CRD $[12,18,29]$ \\
\hline GUCA1B (Guanylate Cyclase Activator 1B) & $6 p 21.1$ & Dominant MD $[12,18]$ \\
\hline $\begin{array}{l}\text { IMPDH1 (Inosine Monophosphate } \\
\text { Dehydrogenase 1) }\end{array}$ & $7 q 32.1$ & Dominant LCA $[2,6,12,18]$ \\
\hline KLHL7 (Kelch Like Family Member 7) & $7 p 15.3$ & {$[12,18]$} \\
\hline NRL (Neural Retina Leucine Zipper) & $14 q 11.2$ & Recessive RP $[12,18]$ \\
\hline $\begin{array}{l}\text { NR2E3 (Nuclear Receptor Subfamily } 2 \text { Group } \\
\text { E Member 3) }\end{array}$ & $15 q 23$ & $\begin{array}{l}\text { Recessive RP }[12,18] \text {, Recessive Goldmann-Favre Syndrome }[12,17,18] \text {, Recessive } \\
\text { ESC }[2,12,17,18]\end{array}$ \\
\hline PRPF3 (Pre-MRNA Processing Factor 3) & $1 q 21.2$ & {$[12,18]$} \\
\hline PRPF6 (Pre-MRNA Processing Factor 6) & $20 q 13.33$ & {$[18]$} \\
\hline PRPF8 (Pre-MRNA Processing Factor 8) & $17 p 13.3$ & {$[12,18]$} \\
\hline PRPF31 (Pre-MRNA Processing Factor 31) & $19 q 13.42$ & {$[12,18]$} \\
\hline PRPH2 (Peripherin 2) & $6 p 21.1$ & $\begin{array}{l}\text { Dominant AVMD }[1,6] \text {, Dominant CRD }[6,12,18] \text {, Dominant Central Areolar } \\
\text { Choroidal Dystrophy }[1,6,12]\end{array}$ \\
\hline RDH12 (Retinol Dehydrogenase 12) & $14 q 24.1$ & Recessive LCA $[2,6,12,18]$ \\
\hline RHO (Rhodopsin) & $3 q 22.1$ & Dominant CSNB $[2,6]$, Recessive $\operatorname{RP}[2,6,12,18]$ \\
\hline RP1 (RP1 Axonemal Microtubule Associated) & $8 q 12.1$ & Recessive RP $[12,18]$ \\
\hline RP9 (RP9 Pre-MRNA Splicing Factor) & $7 p 14.3$ & {$[12,18]$} \\
\hline RPE65 (Retinoid Isomerohydrolase RPE65) & $1 p 31.2$ & Recessive RP $[12,18]$, Recessive LCA $[2,6,18]$ \\
\hline SEMA4A (Semaphorin 4A) & $1 q 22$ & Dominant CRD $[2,6,12,18]$ \\
\hline $\begin{array}{l}\text { SNRNP200 (Small Nuclear } \\
\text { Ribonucleoprotein U5 Subunit 200) }\end{array}$ & $2 q 11.2$ & {$[12,18]$} \\
\hline $\begin{array}{l}\text { TOPORS (TOP1 Binding Arginine/Serine Rich } \\
\text { Protein, E3 Ubiquitin Ligase) }\end{array}$ & $9 p 21.1$ & {$[12,18]$} \\
\hline
\end{tabular}

Abbreviations: RP, Retinitis Pigmentosa; MD, Macular Dystrophy; LCA, Leber Congenital Amaurosis; CRD, Cone-rod Dystrophy; ESC, Enhanced S-cone Syndrome; AVMD, Adult Vitelliform Macular Dystrophy; CSNB, Congenital Stationary Night Blindness. 
Table 4. Genes reported to cause autosomal recessive retinitis pigmentosa.

\begin{tabular}{|c|c|c|}
\hline GENES & CHROMOSOME & OTHER DISEASES \\
\hline ABCA4 (ATP Binding Cassette Subfamily A Member 4) & $1 \mathrm{p} 22.1$ & $\begin{array}{l}\text { Recessive MD [12], Recessive CRD [12, 13], Autosomal Recessive } \\
\text { Stargardt Disease }[12,13,71]\end{array}$ \\
\hline BEST1 (Bestrophin 1) & $11 q 12.3$ & $\begin{array}{l}\text { Dominant Vitreoretinochoroidopathy [12, 32], Recessive } \\
\text { Bestrophinopathy }[12,119], \text { Recessive RP [12], Dominant MD [12, } \\
\text { 13], Best type }[12,13,32,119]\end{array}$ \\
\hline C8ORF37 (Chromosome 8 Open Reading Frame 37) & $8 q 22.1$ & CRD $[6,13,14]$ \\
\hline CERKL (Ceramide Kinase Like) & $2 q 31.3$ & CRD $[12,13,75]$ \\
\hline CNGA3 (Cyclic Nucleotide Gated Channel Subunit Alpha 3) & $2 q 11.2$ & CRD $[12,62]$ and Achromatopsia $[12,126]$ \\
\hline CRB1 (Crumbs Cell Polarity Complex Component 1) & $1 q 31.3$ & Recessive LCA $[12,13]$ and CRD $[12,13,89]$ \\
\hline EYS (Eyes Shut Homolog) & $6 q 12$ & {$[12,13]$} \\
\hline IMPG2 (Interphotoreceptor Matrix Proteoglycan 2) & & {$[12,13]$} \\
\hline LRAT (Lecithin Retinol Acyltransferase) & $4 q 32.1$ & Recessive LCA $[6,12,13,31]$ \\
\hline MERTK (MER Proto-Oncogene, Tyrosine Kinase) & & CRD $[12,13,134]$ \\
\hline NR2E3 (Nuclear Receptor Subfamily 2 Group E Member 3) & $15 q 23$ & Dominant RP $[2,12,13]$, Recessive $\operatorname{ESC}[2,12,13,17]$ \\
\hline NRL (Neural Retina Leucine Zipper) & $14 q 11.2$ & Dominant RP $[12,13]$ \\
\hline PDE6A (Phosphodiesterase 6A) & & {$[12,13]$} \\
\hline PDE6B (Phosphodiesterase 6B) & $4 \mathrm{p} 16.3$ & Dominant CSNB $[6,12,13]$ \\
\hline PDE6G (Phosphodiesterase 6G) & & {$[12,13]$} \\
\hline PROM1 (Prominin 1) & $4 p 15.32$ & $\begin{array}{l}\text { Recessive RP with Macular Degeneration [13], Autosomal } \\
\text { Dominant and Recessive CRD [13, 26], STGD [13, 26, 28] }\end{array}$ \\
\hline RDH12 (Retinol Dehydrogenase 12) & $14 q 24.1$ & Autosomal Recessive LCA $[2,6,13]$ \\
\hline RHO (Rhodopsin) & $3 q 22.1$ & Dominant CSNB $[2,6,11]$, Recessive RP $[2,12,13]$ \\
\hline RP1 (RP1 Axonemal Microtubule Associated) & $8 q 12.1$ & Dominant RP $[12,13]$ \\
\hline RPE65 (Retinoid Isomerohydrolase RPE65) & $1 \mathrm{p} 31.2$ & $\begin{array}{l}\text { Recessive LCA [6, 12], Autosomal Dominant RP }[12,13] \text { and CRD } \\
{[2,12,63]}\end{array}$ \\
\hline SLC7A14 (Solute Carrier Family 7 Member 14) & $3 q 26.2$ & $\operatorname{LCA}[13,131]$ \\
\hline SPATA7 (Spermatogenesis Associated 7) & $14 q 313$ & Autosomal Recessive LCA $[6,12,13,31]$ \\
\hline TTC8 (Tetratricopeptide Repeat Domain 8) & $14 q 32.11$ & Recessive BBS $[6,12,13]$ \\
\hline TULP1 (TUB Like Protein 1) & $6 q 21.31$ & Recessive LCA $[6,12,13,31]$ \\
\hline USH2A (Usherin) & $1 q 41$ & Recessive Usher Syndrome $[12,13,113]$ \\
\hline
\end{tabular}

Abbreviations: MD, Macular Dystrophy; CRD, Cone-Rod Dystrophy; RP, Retinitis Pigmentosa; LCA, Leber Congetinal Amaurosis; ESC, Enhanced S-cone Syndrome; CSNB, Congenital Stationary Night Blindness; BBS, Bardet-Biedl syndrome.

Table 5: Overlap between genes causing retinitis pigmentosa and those causing other inherited retinal diseases.

\begin{tabular}{|c|c|c|c|c|c|c|c|c|c|c|c|c|c|c|c|c|c|c|c|c|c|c|}
\hline $\begin{array}{l}\text { RP-causing Genes } \rightarrow \\
\text { Overlapping Disease } \downarrow\end{array}$ & ষั & 点 & $\frac{\hat{\delta}}{\delta}$ & 这 & $\underset{\mho}{\stackrel{m}{Z}}$ & क्ष & త్ & $\begin{array}{l}\frac{1}{1} \\
\frac{1}{2} \\
\frac{1}{5}\end{array}$ & 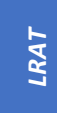 & வัँ & 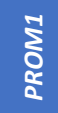 & $\frac{\frac{1}{a}}{\frac{\alpha}{\alpha}}$ & 옳 & ैㅗำ & $\vec{a}$ & $\begin{array}{l}\text { 题 } \\
\frac{1}{\gtrless}\end{array}$ & $\frac{\pi}{\approx}$ & 志 & $\begin{array}{l}\frac{\mathbb{Z}}{\mathbb{T}} \\
\text { ज̆ }\end{array}$ & 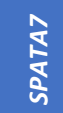 & $\frac{1}{5}$ & \\
\hline $\operatorname{CSNB}[2,6]$ & & & & & & & & & & $x$ & & & $x$ & & & & & & & & & \\
\hline $\operatorname{AVMD}[2,36-38,64]$ & & $x$ & & & & & & & & & & $\mathrm{x}$ & & & & $x$ & & & & & & \\
\hline Achromatopsia [66, 130-133] & & & & & $x$ & & & & & & & & & & & & $x$ & & & & & \\
\hline LCA $[2,6,19,34,35,61,65,66,90,93,135]$ & & & & & & $x$ & $x$ & $x$ & $x$ & & & & & $x$ & & $x$ & $x$ & & $x$ & $x$ & $x$ & \\
\hline $\begin{array}{l}\text { Stargardt Disease }[1,6,36,63,64,75-79,84 \text {, } \\
99,130]\end{array}$ & $x$ & $x$ & & & $X$ & $x$ & & & & & $x$ & $x$ & & & & $X$ & & & & & & $X$ \\
\hline $\begin{array}{l}\text { CRD }[1,2,6,15,19,27,32-35,41,57,66,67, \\
75-79,84,99,116,117,121,130]\end{array}$ & $x$ & & $x$ & $x$ & $x$ & $x$ & $x$ & & & & $x$ & $x$ & & $x$ & $x$ & $x$ & $x$ & $x$ & & & $x$ & $x$ \\
\hline
\end{tabular}

Abbreviations: AVMD, Adult Vitelliform Macular Dystrophy; CSNB, Congenital Stationary Night Blindness; LCA, Leber Congenital Amaurosis; CRD, Cone-Rod Dystrophy; ABCA4, ATP Binding Cassette Subfamily A Member 4; BEST1, Bestrophin 1; C8orf37, Chromosome 8 Open Reading Frame 37; CERKL, Ceramide Kinase Like; CNGA3, Cyclic Nucleotide Gated Channel Subunit Alpha 3; CRB1, Crumbs Cell Polarity Complex Component 1; CRX, Cone-Rod Homeobox; IMPDH1, Inosine Monophosphate Dehydrogenase 1; LRAT, Lecithin Retinol Acyltransferase; PDE6, Phosphodiesterase 6; PROM1, Prominin 1; PRPH2, Peripherin 2; RHO, Rhodopsin; RDH12, Retinol Dehydrogenase 12; RP1, RP1 Axonemal Microtubule Associated; RPE65, Retinoid Isomerohydrolase RPE65; RPGR, Retinitis Pigmentosa GTPase Regulator; SEMA4, Semaphorin 4A; SLC7A14, Solute Carrier Family 7 Member 14; SPATA7, Spermatogenesis Associated 7; TULP1, TUB Like Protein 1; USH2A, Usherin. 
Table 6. Abbreviations used in the text

\begin{tabular}{|c|c|}
\hline Abbreviation & Full description \\
\hline AVMD & Adult onset Vitelliform Macular Dystrophy \\
\hline ABC & ATP-Binding Cassette transporter protein \\
\hline adRP & autosomal dominant RP \\
\hline adSTGD1 & autosomal dominant STGD1-like \\
\hline arB & autosomal recessive bestrophinopathy \\
\hline arRP & autosomal recessive RP \\
\hline arSTGD1 & autosomal recessive Stargardt Disease \\
\hline BBS & Bardet-Biedl Syndrome \\
\hline BVMD & Best Vitelliform Macular Dystrophy \\
\hline CTL & C-Type Lectin \\
\hline CCO & Carotenoid Cleavage Oxygenase \\
\hline CD & Cone Dystrophy \\
\hline CRD & Cone-Rod Dystrophy \\
\hline CSNB & Congenital Stationary Night Blindness \\
\hline CC & Connecting Cilium \\
\hline CRB1 & CRumBs Homologue 1 \\
\hline cGMP & Cyclic Guanosine MonoPhosphate \\
\hline CME & Cystoid Macular Edema \\
\hline DBD & DNA-Binding Domain \\
\hline ERG & ElectroRetinoGram \\
\hline ESC & Enhanced S-Cone syndrome \\
\hline EGF & Epidermal Growth Factor \\
\hline ffERG & Full-Field ERG \\
\hline GPCR & G Protein Coupled Receptors \\
\hline iPSCs & Induced Pluripotent Stem Cells \\
\hline IRDs & Inherited Retinal Diseases \\
\hline IS & Inner Segment \\
\hline LCA & Leber Congenital Amaurosis \\
\hline LBD & Ligand-Binding Domain \\
\hline MD & Macular Dystrophies \\
\hline mERG & Multifocal ERG \\
\hline NRPE & N-Retinylidene-PhosphatidylEthanolamine \\
\hline NGS & Next-Generation Sequencing \\
\hline OCT & Optical Coherence Tomography \\
\hline OSs & Outer Segments \\
\hline PRPH2 & Peripherin 2 \\
\hline PE & PhosphatidylEthanolamine \\
\hline PDE6 & PhosphoDiEsterase 6 \\
\hline PRPF31 & PRe-mRNA Processing Factor 31 \\
\hline PROM-1 & PROMinin like-1 \\
\hline RPE & Retinal Pigment Epithelium \\
\hline RP & Retinitis Pigmentosa \\
\hline RP1 & Retinitis Pigmentosa 1 \\
\hline RP2 & Retinitis Pigmentosa 2 \\
\hline RP4 & Retinitis Pigmentosa 4 \\
\hline RPGR & Retinitis Pigmentosa GTPase Regulator \\
\hline RPGRIP1 & Retinitis Pigmentosa GTPase Regulator Interacting Protein 1 \\
\hline RHO & RHodOpsin \\
\hline RCD & Rod-Cone Dystrophy \\
\hline SnRNP & Small Nuclear RiboNucleoProtein \\
\hline TULP1 & TUbby-Like Protein 1 \\
\hline USH2 & USHer Syndrome Type 2 \\
\hline VMD & Vitelliform Macular Dystrophy \\
\hline XLCD & X-Linked Cone Dystrophy \\
\hline XLMD & X-Linked Macular Dystrophy \\
\hline $\mathbf{x I R P}$ & X-Linked RP \\
\hline
\end{tabular}




\section{CONCLUSIONS}

$\mathrm{RP}$ is a genetically complicated and heterogeneous disease. To date, approximately 80 genes have been implicated in non-syndromic RP and 30 genes in syndromic RP. The extreme heterogeneity that characterizes RP has led to many attempts to map and analyze the genes that contribute to the appearance and progression of several RP forms, a demanding task as these genes belong to several groups (i.e., genes that encode proteins of the visual cascade, genes encoding proteins of the visual cycle, mitochondrial genes, etc.). To date, approximately 27 adRP, 55 arRP, and 6 xIRP genes have been reported to be pathogenic according to the RetNet and Genecards databases, whereas several genes may be implicated in different patterns of RP inheritance. $R H O$ is the gene most often associated with adRP, USH2A with arRP, and RPGR with xIRP.

Specific genotyping microarrays, gene-by-gene analysis by Sanger sequencing, linkage mapping, NGS, and deletion detection are mainly used for the genetic diagnosis of IRDs, including RP. The main long-term objective of research on mutations associated with RP pathogenesis is the adoption of wide genetic testing. This may provide appropriate information for clinical care and counseling of patients with RP. The expectation is that the eventual verification of disease pathology will offer novel treatments and cure. The ultimate research target is to permit the interpretation of variants and reconciliation of the diagnosis with molecular findings. Such an eventuality will provide meaningful information to clinicians and provide useful counseling to patients. Thus, it is crucial for future studies to attempt an analysis and detailed mapping of the genes that contribute to the appearance and progression of each type of RP.

In addition, a detailed map of RP pathogenic genes could provide vital information for future research on RP genetics and therapy methods, particularly gene therapy. By presenting the major genes involved in RP pathogenesis, future therapy methods may focus on exact mutations and variants that provide accurate treatment by targeting specific loci.

\section{ETHICS DECLARATIONS}

Ethical approval: This study was an observational bibliographic study and no ethical approval was required. Conflict of interest: The authors have no conflicts of interest to declare.

\section{FUNDING}

None.

\section{ACKNOWLEDGMENT}

None.

\section{REFERENCES}

1. Huang L, Zhang $Q$, Huang $X, Q u$ C, Ma S, Mao Y, et al. Mutation screening in genes known to be responsible for Retinitis Pigmentosa in 98 Small Han Chinese Families. Sci Rep. 2017;7(1):1948. doi: 10.1038/s41598-017-00963-6 pmid 28512305

2. Daiger SP, Bowne SJ, Sullivan LS. Perspective on genes and mutations causing retinitis pigmentosa Arch Ophthalmol. 2007;125(2):151-8. doi: 10.1001/archopht.125.2.151 pmid: 17296890

3. Perez-Carro R, Corton M, Sanchez-Navarro I, Zurita O, SanchezBolivar N, Sanchez-Alcudia R, et al. Panel-based NGS Reveals Novel Pathogenic Mutations in Autosomal Recessive Retinitis Pigmentosa. Sci Rep. 2016;6:19531. doi: 10.1038/srep19531 pmid: 26806561

4. Ezquerra-Inchausti $M$, Barandika $O$, Anasagasti A, Irigoyen $C$, Lopez de Munain A, Ruiz-Ederra J. High prevalence of mutations affecting the splicing process in a Spanish cohort with autosomal dominant retinitis pigmentosa. Sci Rep. 2017;7:39652. doi: 10.1038/srep39652 pmid: 28045043

5. Hamel C. Retinitis pigmentosa. Orphanet J Rare Dis. 2006;1:40. doi: 10.1186/1750-1172-1-40 pmid: 17032466

6. Daiger SP, Sullivan LS, Bowne SJ. Genes and mutations causing retinitis pigmentosa. Clin Genet. 2013;84(2):132-41. doi: 10.1111/cge.12203 pmid: 23701314

7. Verbakel SK, van Huet RAC, Boon CJF, den Hollander Al, Collin RWJ, Klaver CCW, et al. Non-syndromic retinitis pigmentosa. Prog Retin Eye Res. 2018;66:157-86. doi: 10.1016/j.preteyeres.2018.03.005 pmid: 29597005

8. Pagon RA. Retinitis pigmentosa. Surv Ophthalmol. 1988;33(3):137-77. doi: 10.1016/0039-6257(88)90085-9 pmid: 3068820

9. Hartong DT, Berson EL, Dryja TP. Retinitis pigmentosa. Lancet. 2006;368(9549):1795-809. doi: 10.1016/S0140-6736(06)69740-7 pmid: 17113430

10. Jiang J, Wu X, Shen D, Dong L, Jiao X, Hejtmancik JF, et al. Analysis of RP2 and RPGR Mutations in Five X-Linked Chinese Families with Retinitis Pigmentosa. Sci Rep. 2017;7:44465. doi: 10.1038/srep44465 pmid: 28294154

11. Wang J, Xu D, Zhu T, Zhou Y, Chen X, Wang F, et al. Identification of two novel RHO mutations in Chinese retinitis pigmentosa patients. Exp Eye Res. 2019;188:107726. doi: 10.1016/j.exer.2019.107726 pmid: 31319082

12. Ferrari S, Di lorio E, Barbaro V, Ponzin D, Sorrentino FS, Parmeggiani F. Retinitis pigmentosa: genes and disease mechanisms. Curr Genomics. 2011;12(4):238-49. doi: 10.2174/138920211795860107 pmid: 22131869

13. Akkaya S. Rate of Parental Consanguineous Marriage among Patients with Visual Impairments in Turkey. Med Hypothesis Discov Innov Ophthalmol. 2016;5(4):115-20. pmid: 28293658 
14. Ali MU, Rahman MSU, Cao J, Yuan PX. Genetic characterization and disease mechanism of retinitis pigmentosa; current scenario. 3 Biotech. 2017;7(4):251. doi: 10.1007/s13205-017-0878-3 pmid: 28721681

15. Chen $X$, Sheng $X$, Liu $Y$, Li Z, Sun $X$, Jiang $C$, et al. Distinct mutations with different inheritance mode caused similar retinal dystrophies in one family: a demonstration of the importance of genetic annotations in complicated pedigrees. J Transl Med. 2018;16(1):145. doi: 10.1186/s12967-018-1522-7 pmid: 29843741

16. Domanico D, Fragiotta S, Cutini A, Grenga PL, Vingolo EM. Psychosis, Mood and Behavioral Disorders in Usher Syndrome: Review of the Literature. Med Hypothesis Discov Innov Ophthalmol. 2015;4(2):50-5. pmid: 26060830

17. Abdulridha-Aboud W, Kjellstrom U, Andreasson S, Ponjavic V. Characterization of macular structure and function in two Swedish families with genetically identified autosomal dominant retinitis pigmentosa. Mol Vis. 2016;22:362-73. pmid: 27212874

18. Sun X, Park JH, Gumerson J, Wu Z, Swaroop A, Qian H, et al. Loss of RPGR glutamylation underlies the pathogenic mechanism of retinal dystrophy caused by TTLL5 mutations. Proc Natl Acad Sci U S A. 2016;113(21):E2925-34. doi: 10.1073/pnas.1523201113 pmid: 27162334

19. Phelan JK, Bok D. A brief review of retinitis pigmentosa and the identified retinitis pigmentosa genes. Mol Vis. 2000;6:116-24. pmid: 10889272

20. Daiger SP, Bowne SJ, Sullivan LS. Genes and Mutations Causing Autosomal Dominant Retinitis Pigmentosa. Cold Spring Harb Perspect Med. 2014;5(10):a017129. doi: 10.1101/cshperspect.a017129 pmid: 25304133

21. Kabir F, Ullah I, Ali S, Gottsch AD, Naeem MA, Assir MZ, et al. Loss of function mutations in RP1 are responsible for retinitis pigmentosa in consanguineous familial cases. Mol Vis. 2016;22:610-25. pmid: 27307693

22. Uy HS, Chan PS, Cruz FM. Stem cell therapy: a novel approach for vision restoration in retinitis pigmentosa. Med Hypothesis Discov Innov Ophthalmol. 2013;2(2):52-5. pmid: 24600643

23. Panfoli I. Beneficial effect of antioxidants in retinopathies: a new hypothesis. Med Hypothesis Discov Innov Ophthalmol. 2012;1(4):76-9. pmid: 24600629

24. Van Cauwenbergh C, Coppieters F, Roels D, De Jaegere S, Flipts H, De Zaeytijd J, et al. Mutations in Splicing Factor Genes Are a Major Cause of Autosomal Dominant Retinitis Pigmentosa in Belgian Families. PLoS One. 2017;12(1):e0170038. doi: 10.1371/journal.pone.0170038 pmid: 28076437

25. Yu X, Shi W, Cheng L, Wang Y, Chen D, Hu X, et al. Identification of a rhodopsin gene mutation in a large family with autosomal dominant retinitis pigmentosa. Sci Rep. 2016;6:19759. doi: 10.1038/srep19759 pmid: 26794436

26. Beryozkin A, Levy G, Blumenfeld A, Meyer S, Namburi P, Morad Y, et al. Genetic Analysis of the Rhodopsin Gene Identifies a Mosaic Dominant Retinitis Pigmentosa Mutation in a Healthy Individual. Invest Ophthalmol Vis Sci. 2016;57(3):940-7. doi: 10.1167/iovs.1518702 pmid: 26962691

27. Martin-Merida I, Aguilera-Garcia D, Fernandez-San Jose $P$, BlancoKelly F, Zurita O, Almoguera B, et al. Toward the Mutational Landscape of Autosomal Dominant Retinitis Pigmentosa: A Comprehensive Analysis of 258 Spanish Families. Invest Ophthalmol Vis Sci. 2018;59(6):2345-54. doi: 10.1167/iovs.1823854 pmid: 29847639
28. Roshandel D, Rafati M, Khorami S, Novin Baheran N, Jalali S, Tabatabaie $R$, et al. Rhodopsin gene mutation analysis in Iranian patients with autosomal dominant retinitis pigmentosa. Int Ophthalmol. 2019;39(11):2523-31. doi: 10.1007/s10792-01901099-4 pmid: 30972525

29. Koyanagi Y, Akiyama M, Nishiguchi KM, Momozawa Y, Kamatani $Y$, Takata S, et al. Genetic characteristics of retinitis pigmentosa in 1204 Japanese patients. J Med Genet. 2019;56(10):662-70. doi: 10.1136/jmedgenet-2018-105691 pmid: 31213501

30. Kim MS, Joo K, Seong MW, Kim MJ, Park KH, Park SS, et al. Genetic Mutation Profiles in Korean Patients with Inherited Retinal Diseases. J Korean Med Sci. 2019;34(21):e161. doi: 10.3346/jkms.2019.34.e161 pmid: 31144483

31. Conley SM, Stuck MW, Watson JN, Naash MI. Rom1 converts Y141C-Prph2-associated pattern dystrophy to retinitis pigmentosa. Hum Mol Genet. 2017;26(3):509-18. doi: 10.1093/hmg/ddw408 pmid: 28053051

32. Tsokolas G, Almuhtaseb H, Griffiths H, Shawkat F, Pengelly RJ, Sarah E, et al. Long term follow-up of a family with GUCY2D dominant cone dystrophy. Int J Ophthalmol. 2018;11(12):1945-50. doi: 10.18240/ijo.2018.12.12 pmid: 30588428

33. Birtel J, Eisenberger T, Gliem M, Muller PL, Herrmann P, Betz C, et al. Clinical and genetic characteristics of 251 consecutive patients with macular and cone/cone-rod dystrophy. Sci Rep. 2018;8(1):4824. doi: 10.1038/s41598-018-22096-0 pmid 29555955

34. Birtel J, Gliem M, Mangold E, Muller PL, Holz FG, Neuhaus C, et al. Next-generation sequencing identifies unexpected genotypephenotype correlations in patients with retinitis pigmentosa. PLoS One. 2018;13(12):e0207958. doi: 10.1371/journal.pone.0207958 pmid: 30543658

35. Huang H, Wang Y, Chen $\mathrm{H}$, Chen $\mathrm{Y}, \mathrm{Wu}$ J, Chiang PW, et al. Targeted next generation sequencing identified novel mutations in RPGRIP1 associated with both retinitis pigmentosa and Leber's congenital amaurosis in unrelated Chinese patients. Oncotarget. 2017;8(21):35176-83. doi: 10.18632/oncotarget.17052 pmid: 28456785

36. Xiang $\mathrm{Q}$, Cao $\mathrm{Y}, \mathrm{Xu} \mathrm{H}$, Guo Y, Yang $Z$, Xu L, et al. Identification of novel pathogenic ABCA4 variants in a Han Chinese family with STGD. Biosci Rep. 2019;39(1). doi: 10.1042/BSR20180872 pmid: 30563929

37. Brandl C, Schulz HL, Charbel Issa P, Birtel J, Bergholz R, Lange C, et al. Mutations in the Genes for Interphotoreceptor Matrix Proteoglycans, IMPG1 and IMPG2, in Patients with Vitelliform Macular Lesions. Genes (Basel). 2017;8(7). doi: 10.3390/genes8070170 pmid: 28644393

38. Grunin M, Tiosano L, Jaouni T, Averbukh E, Sharon D, Chowers I. Evaluation of the association of single nucleotide polymorphisms in the PRPH2 gene with adult-onset foveomacular vitelliform dystrophy. Ophthalmic Genet. 2016;37(3):285-9. doi: 10.3109/13816810.2015.1059456 pmid: 26849151

39. Liu S, Xie L, Yue J, Ma T, Peng C, Qiu B, et al. Whole-exome sequencing identifies a novel homozygous frameshift mutation in the PROM1 gene as a causative mutation in two patients with sporadic retinitis pigmentosa. Int J Mol Med. 2016;37(6):1528-34. doi: 10.3892/ijmm.2016.2551 pmid: 27082927

40. Lu L, Wang X, Lo D, Weng J, Liu X, Yang J, et al. Novel mutations in CRB1 gene identified in a chinese pedigree with retinitis pigmentosa by targeted capture and next generation sequencing. Oncotarget. 2016;7(48):79797-804. doi 10.18632/oncotarget.12971 pmid: 27806333 
41. Ravesh Z, El Asrag ME, Weisschuh N, McKibbin M, Reuter P, Watson CM, et al. Novel C8orf37 mutations cause retinitis pigmentosa in consanguineous families of Pakistani origin. Mol Vis. 2015;21:236-43. pmid: 25802487

42. Parmeggiani F, Barbaro V, Migliorati A, Raffa P, Nespeca $P$, De Nadai $K$, et al. Novel variants of RPGR in X-linked retinitis pigmentosa families and genotype-phenotype correlation. Eur J Ophthalmol. 2017;27(2):240-8. doi: 10.5301/ejo.5000879 pmid: 27768226

43. Manes G, Guillaumie T, Vos WL, Devos A, Audo I, Zeitz C, et al. High prevalence of $\mathrm{PRPH} 2$ in autosomal dominant retinitis pigmentosa in france and characterization of biochemical and clinical features. Am J Ophthalmol. 2015;159(2):302-14. doi: 10.1016/j.ajo.2014.10.033 pmid: 25447119

44. Zhong Z, Yan M, Sun W, Wu Z, Han L, Zhou Z, et al. Two novel mutations in PRPF3 causing autosomal dominant retinitis pigmentosa. Sci Rep. 2016;6:37840. doi: 10.1038/srep37840 pmid: 27886254

45. Xiao J, Guo X, Wang Y, Shao M, Wei X, Du L, et al. Identification of a Disease-Causing Mutation in a Chinese Patient with Retinitis Pigmentosa by Targeted Next-Generation Sequencing. Eur J Ophthalmol. 2017;27(6):791-6. doi: 10.5301/ejo.5000971 pmid: 28430325

46. Wu Z, Zhong M, Li M, Huang $\mathrm{H}$, Liao J, Lu A, et al. Mutation Analysis of Pre-mRNA Splicing Genes PRPF31, PRPF8, and SNRNP200 in Chinese Families with Autosomal Dominant Retinitis Pigmentosa. Curr Mol Med. 2018;18(5):287-94. doi: 10.2174/1566524018666181024160452 pmid: 30360737

47. Chen X, Liu Y, Sheng X, Tam PO, Zhao K, Chen X, et al. PRPF4 mutations cause autosomal dominant retinitis pigmentosa. Hum Mol Genet. 2014;23(11):2926-39. doi: 10.1093/hmg/ddu005 pmid: 24419317

48. Yang Y, Tian D, Lee J, Zeng J, Zhang H, Chen S, et al. Clinical and genetic identification of a large chinese family with autosomal dominant retinitis pigmentosa. Ophthalmic Genet. 2015;36(1):649. doi: 10.3109/13816810.2013.809458 pmid: 23834559

49. Rose AM, Luo R, Radia UK, Bhattacharya SS. Gene of the month: PRPF31. J Clin Pathol. 2017;70(9):729-32. doi: 10.1136/jclinpath2016-203971 pmid: 28663330

50. Xiao X, Cao Y, Zhang Z, Xu Y, Zheng Y, Chen L, et al. Novel Mutations in PRPF31 Causing Retinitis Pigmentosa Identified Using Whole-Exome Sequencing. Invest Ophthalmol Vis Sci. 2017;58(14):6342-50. doi: 10.1167/iovs.17-22952 pmid: 29260190

51. Rose AM, Shah AZ, Venturini G, Krishna A, Chakravarti A, Rivolta C, et al. Transcriptional regulation of PRPF31 gene expression by MSR1 repeat elements causes incomplete penetrance in retinitis pigmentosa. Sci Rep. 2016;6:19450. doi: 10.1038/srep19450 pmid: 26781568

52. Xie D, Peng K, Yi Q, Liu W, Yang Y, Sun K, et al. Targeted Next Generation Sequencing Revealed Novel PRPF31 Mutations in Autosomal Dominant Retinitis Pigmentosa. Genet Test Mol Biomarkers. 2018;22(7):425-32. doi: 10.1089/gtmb.2018.0036 pmid: 29957067

53. Martin-Merida I, Sanchez-Alcudia R, Fernandez-San Jose $P$, Blanco-Kelly F, Perez-Carro R, Rodriguez-Jacy da Silva L, et al. Analysis of the PRPF31 Gene in Spanish Autosomal Dominant Retinitis Pigmentosa Patients: A Novel Genomic Rearrangement. Invest Ophthalmol Vis Sci. 2017;58(2):1045-53. doi: 10.1167/iovs.16-20515 pmid: 28192796
54. Zahid S, Branham K, Schlegel D, Pennesi ME, Michaelides M, Heckenlively J, et al. Retinal dystrophy gene atlas. Berlin: Springer; 2018.

55. Riera M, Abad-Morales V, Navarro R, Ruiz-Nogales S, MendezVendrell $\mathrm{P}$, Corcostegui $\mathrm{B}$, et al. Expanding the retinal phenotype of RP1: from retinitis pigmentosa to a novel and singular macular dystrophy. $\mathrm{Br} J$ Ophthalmol. 2020;104(2):173-81. doi: 10.1136/bjophthalmol-2018-313672 pmid: 31079053

56. Kurata K, Hosono K, Hotta Y. Clinical and genetic findings of a Japanese patient with RP1-related autosomal recessive retinitis pigmentosa. Doc Ophthalmol. 2018;137(1):47-56. doi: 10.1007/s10633-018-9649-7 pmid: 30027431

57. Verbakel SK, van Huet RAC, den Hollander Al, Geerlings MJ, Kersten E, Klevering BJ, et al. Macular Dystrophy and Cone-Rod Dystrophy Caused by Mutations in the RP1 Gene: Extending the RP1 Disease Spectrum. Invest Ophthalmol Vis Sci. 2019;60(4):1192-203. doi: 10.1167/iovs.18-26084 pmid: 30913292

58. Wang L, Qi A, Pan H, Liu B, Feng J, Chen W, et al. A novel CRX frameshift mutation causing cone-rod dystrophy in a Chinese family: A case report. Medicine (Baltimore). 2018;97(32):e11499. doi: 10.1097/MD.0000000000011499 pmid: 30095615

59. Zhu $Y$, Tan $H$, Zeng J, Tao D, Ma Y, Liu Y. A novel CRX variant (p.R98X) is identified in a Chinese family of Retinitis pigmentosa with atypical and mild manifestations. Genes Genomics. 2019;41(3):359-66. doi: 10.1007/s13258-018-0763-4 pmid: 30460480

60. Chapi M, Sabbaghi H, Suri F, Alehabib E, Rahimi-Aliabadi S, Jamali $F$, et al. Incomplete penetrance of CRX gene for autosomal dominant form of cone-rod dystrophy. Ophthalmic Genet. 2019;40(3):259-66. doi: 10.1080/13816810.2019.1622023 pmid 31215831

61. Walia S, Fishman GA, Jacobson SG, Aleman TS, Koenekoop RK, Traboulsi El, et al. Visual acuity in patients with Leber's congenital amaurosis and early childhood-onset retinitis pigmentosa. Ophthalmology. 2010;117(6):1190-8. doi 10.1016/j.ophtha.2009.09.056 pmid: 20079931

62. Jauregui R, Park KS, Tsang SH. Two-year progression analysis of RPE65 autosomal dominant retinitis pigmentosa. Ophthalmic Genet. 2018;39(4):544-9. doi: 10.1080/13816810.2018.1484929 pmid: 29947567

63. Choi E, Suh S, Sander C, Hernandez C, Bulman E, Khadka N. Insights into the pathogenesis of dominant retinitis pigmentosa associated with a D477G mutation in RPE65. Hum Mol Genet. 2018;27(13):2225-43. doi: 10.1093/hmg/ddy128

64. Hull S, Mukherjee R, Holder GE, Moore AT, Webster AR. The clinical features of retinal disease due to a dominant mutation in RPE65. Mol Vis. 2016;22:626-35. pmid: 27307694

65. Glen WB, Jr., Peterseim MMW, Badilla R, Znoyko I, Bourg A, Wilson $R$, et al. A high prevalence of biallelic RPE65 mutations in Costa Rican children with Leber congenital amaurosis and early-onset retinal dystrophy. Ophthalmic Genet. 2019;40(2):110-7. doi: 10.1080/13816810.2019.1582069 pmid: 30870047

66. Hohman TC. Hereditary Retinal Dystrophy. Handb Exp Pharmacol. 2017;242:337-67. doi: 10.1007/164_2016_91 pmid: 28035529

67. Li S, Xiao X, Yi Z, Sun W, Wang P, Zhang Q. RPE65 mutation frequency and phenotypic variation according to exome sequencing in a tertiary centre for genetic eye diseases in China. Acta Ophthalmol. 2020;98(2):e181-e90. doi: 10.1111/aos.14181 pmid: 31273949 
68. Chebil A, Falfoul Y, Habibi I, Munier F, Schorderet D, El Matri L. [Genotype-phenotype correlation in ten Tunisian families with non-syndromic retinitis pigmentosa]. J Fr Ophtalmol. 2016;39(3):277-86. doi: 10.1016/j.jfo.2015.08.013 pmid: 26868535

69. Jakobsson C, Othman IS, Munier FL, Schorderet DF, Abouzeid H. Cone-rod dystrophy caused by a novel homozygous RPE65 mutation in Leber congenital amaurosis. Klin Monbl Augenheilkd. 2014;231(4):405-10. doi: 10.1055/s-0034-1368221 pmid: 24771178

70. Astuti GD, Bertelsen M, Preising MN, Ajmal M, Lorenz B, Faradz $\mathrm{SM}$, et al. Comprehensive genotyping reveals RPE65 as the most frequently mutated gene in Leber congenital amaurosis in Denmark. Eur J Hum Genet. 2016;24(7):1071-9. doi: 10.1038/ejhg.2015.241 pmid: 26626312

71. Liu J, Bu J. A Gene Scan Study of RPE65 in Chinese Patients with Leber Congenital Amaurosis. Chin Med J (Engl). 2017;130(22):2709-12. doi: 10.4103/0366-6999.218007 pmid: 29133760

72. Smaragda K, Vassiliki K, George K, Polixeni S, Christoforos G, Anastasios A, et al. Mutation Spectrum of the ABCA4 Gene in a Greek Cohort with Stargardt Disease: Identification of Novel Mutations and Evidence of Three Prevalent Mutated Alleles. J Ophthalmol. 2018;2018:5706142. doi: 10.1155/2018/5706142 pmid: 29854428

73. Huang L, Zhang Q, Li S, Guan L, Xiao X, Zhang J, et al. Exome sequencing of 47 chinese families with cone-rod dystrophy: mutations in 25 known causative genes. PLoS One. 2013;8(6):e65546. doi: 10.1371/journal.pone.0065546 pmid: 23776498

74. Makelainen S, Godia M, Hellsand M, Viluma A, Hahn D, Makdoumi $\mathrm{K}$, et al. An ABCA4 loss-of-function mutation causes a canine form of Stargardt disease. PLoS Genet. 2019;15(3):e1007873. doi: 10.1371/journal.pgen.1007873 pmid: 30889179

75. Huang $X$, Yuan L, Xu H, Zheng W, Cao Y, Yi J, et al. Identification of a Novel Mutation in the ABCA4 Gene in a Chinese Family with Retinitis Pigmentosa Using Exome Sequencing. Biosci Rep. 2018;38(2). doi: 10.1042/BSR20171300 pmid: 29437900

76. Sheremet NL, Grushke IG, Zhorzholadze NV, Ronzina IA, Mikaelyan AA, Tanas AS, et al. [Clinical polymorphism of splice site mutations in the ABCA4 gene]. Vestn Oftalmol. 2018;134(6):83-93. doi: 10.17116/oftalma201813406183 pmid: 30721205

77. Jiang F, Pan Z, Xu K, Tian L, Xie Y, Zhang X, et al. Screening of ABCA4 Gene in a Chinese Cohort With Stargardt Disease or Cone-Rod Dystrophy With a Report on 85 Novel Mutations. Invest Ophthalmol Vis Sci. 2016;57(1):145-52. doi: 10.1167/iovs.1518190 pmid: 26780318

78. Sheremet NL, Grushke IG, Zhorzholadze NV, Tanas AS, Strelnikov VV. [Inherited retinal diseases in patients with ABCA4 gene mutations]. Vestn Oftalmol. 2018;134(4):68-73. doi: 10.17116/oftalma201813404168 pmid: 30166513

79. Biswas P, Duncan JL, Maranhao B, Kozak I, Branham K, Gabriel L, et al. Genetic analysis of 10 pedigrees with inherited retinal degeneration by exome sequencing and phenotype-genotype association. Physiol Genomics. 2017;49(4):216-29. doi: 10.1152/physiolgenomics.00096.2016 pmid: 28130426

80. Mayer AK, Rohrschneider K, Strom TM, Glockle N, Kohl S, Wissinger $B$, et al. Homozygosity mapping and whole-genome sequencing reveals a deep intronic PROM1 mutation causing cone-rod dystrophy by pseudoexon activation. Eur J Hum Genet. 2016;24(3):459-62. doi: 10.1038/ejhg.2015.144 pmid: 26153215
81. Sharon D, Ben-Yosef T, Pras E, Goldenberg-Cohen N, Gradstein L, Shomron N, et al. [the Israeli Inherited Retinal Diseases Consortium (lirdc)- Clinical-Genetic Mapping and Future Perspectives]. Harefuah. 2019;158(2):91-5. pmid: 30779484

82. Quinn PM, Mulder AA, Henrique Alves C, Desrosiers M, de Vries SI, Klooster J, et al. Loss of CRB2 in Muller glial cells modifies a CRB1associated retinitis pigmentosa phenotype into a Leber congenital amaurosis phenotype. Hum Mol Genet. 2019;28(1):105-23. doi: 10.1093/hmg/ddy337 pmid: 30239717

83. Wawrocka A, Skorczyk-Werner A, Wicher K, Niedziela Z, Ploski R, Rydzanicz $\mathrm{M}$, et al. Novel variants identified with next-generation sequencing in Polish patients with cone-rod dystrophy. Mol Vis. 2018;24:326-39. pmid: 29769798

84. Liang J, She X, Chen J, Zhai Y, Liu Y, Zheng K, et al. Identification of novel PROM1 mutations responsible for autosomal recessive maculopathy with rod-cone dystrophy. Graefes Arch Clin Exp Ophthalmol. 2019;257(3):619-28. doi: 10.1007/s00417-01804206-w pmid: 30588538

85. Schroeder M, Kjellstrom U. Full-field ERG as a predictor of the natural course of ABCA4-associated retinal degenerations. Mol Vis. 2018;24:1-16. pmid: 29386879

86. Motta FL, Salles MV, Costa KA, Filippelli-Silva R, Martin RP, Sallum JMF. The correlation between CRB1 variants and the clinical severity of Brazilian patients with different inherited retinal dystrophy phenotypes. Sci Rep. 2017;7(1):8654. doi: 10.1038/s41598-017-09035-1 pmid: 28819299

87. Khan KN, Robson A, Mahroo OAR, Arno G, Inglehearn CF, Armengol $\mathrm{M}$, et al. A clinical and molecular characterisation of CRB1-associated maculopathy. Eur J Hum Genet. 2018;26(5):68794. doi: 10.1038/s41431-017-0082-2 pmid: 29391521

88. Yang $Y$, Yang $Y$, Huang L, Zhai $Y$, Li J, Jiang $Z$, et al. Whole exome sequencing identified novel CRB1 mutations in Chinese and Indian populations with autosomal recessive retinitis pigmentosa. Sci Rep. 2016;6:33681. doi: 10.1038/srep33681 pmid: 27670293

89. Shen T, Guan L, Li S, Zhang J, Xiao X, Jiang H, et al. Mutation analysis of Leber congenital amaurosisassociated genes in patients with retinitis pigmentosa. Mol Med Rep. 2015;11(3):1827-32. doi: 10.3892/mmr.2014.2894 pmid: 25377065

90. Srilekha S, Arokiasamy T, Srikrupa NN, Umashankar V, Meenakshi $\mathrm{S}$, Sen $\mathrm{P}$, et al. Homozygosity Mapping in Leber Congenital Amaurosis and Autosomal Recessive Retinitis Pigmentosa in South Indian Families. PLoS One. 2015;10(7):e0131679. doi: 10.1371/journal.pone.0131679 pmid: 26147992

91. Talib M, van Schooneveld MJ, van Genderen MM, Wijnholds J, Florijn RJ, Ten Brink JB, et al. Genotypic and Phenotypic Characteristics of CRB1-Associated Retinal Dystrophies: A LongTerm Follow-up Study. Ophthalmology. 2017;124(6):884-95. doi: 10.1016/j.ophtha.2017.01.047 pmid: 28341475

92. Guo X, Li J, Wang Q, Shu Y, Wang J, Chen L, et al. Identification of CRB1 mutations in two Chinese consanguineous families exhibiting autosomal recessive retinitis pigmentosa. Mol Med Rep. 2019;20(3):2922-8. doi: 10.3892/mmr.2019.10495 pmid: 31322236

93. Saberi M, Golchehre Z, Karamzade A, Entezam M, Eshaghkhani Y, Alavinejad E, et al. CRB1-Related Leber Congenital Amaurosis: Reporting Novel Pathogenic Variants and a Brief Review on Mutations Spectrum. Iran Biomed J. 2019;23(5):362-8. pmid: 31103025

94. Khan AO, Aldahmesh MA, Abu-Safieh L, Alkuraya FS. Childhood cone-rod dystrophy with macular cystic degeneration from 
recessive CRB1 mutation. Ophthalmic Genet. 2014;35(3):130-7. doi: 10.3109/13816810.2013.804097 pmid: 23767994

95. Mathijssen IB, Florijn RJ, van den Born LI, Zekveld-Vroon RC, Ten Brink JB, Plomp AS, et al. Long-term follow-up of patients with retinitis pigmentosa type 12 caused by CRB1 mutations: a severe phenotype with considerable interindividual variability. Retina. 2017;37(1):161-72. doi: 10.1097/IAE.0000000000001127 pmid: 27380427

96. Jinda W, Taylor TD, Suzuki Y, Thongnoppakhun W, Limwongse C, Lertrit $P$, et al. Whole exome sequencing in Thai patients with retinitis pigmentosa reveals novel mutations in six genes. Invest Ophthalmol Vis Sci. 2014;55(4):2259-68. doi: 10.1167/iovs.1313567 pmid: 24618324

97. Weisschuh N, Feldhaus B, Khan MI, Cremers FPM, Kohl S, Wissinger B, et al. Molecular and clinical analysis of 27 German patients with Leber congenital amaurosis. PLoS One. 2018;13(12):e0205380. doi: 10.1371/journal. pone.0205380 pmid: 30576320

98. Del Pozo-Valero M, Martin-Merida I, Jimenez-Rolando B, Arteche A, Avila-Fernandez A, Blanco-Kelly F, et al. Expanded Phenotypic Spectrum of Retinopathies Associated with Autosomal Recessive and Dominant Mutations in PROM1. Am J Ophthalmol. 2019;207:204-14. doi: 10.1016/j.ajo.2019.05.014 pmid: 31129250

99. Arrigoni FI, Matarin M, Thompson PJ, Michaelides M, McClements $\mathrm{ME}$, Redmond $\mathrm{E}$, et al. Extended extraocular phenotype of PROM1 mutation in kindreds with known autosomal dominant macular dystrophy. Eur J Hum Genet. 2011;19(2):131-7. doi: 10.1038/ejhg.2010.147 pmid: 20859302

100. Permanyer J, Navarro R, Friedman J, Pomares E, CastroNavarro J, Marfany G, et al. Autosomal recessive retinitis pigmentosa with early macular affectation caused by premature truncation in PROM1. Invest Ophthalmol Vis Sci. 2010;51(5):265663. doi: $10.1167 /$ iovs.09-4857 pmid: 20042663

101. Sheremet NL, Zhorzholadze NV, Ronzina IA, Grushke IG, Kurbatov SA, Chukhrova AL, et al. [Molecular genetic diagnosis of STGD]. Vestn Oftalmol. 2017;133(4):4-11. doi: 10.17116/oftalma201713344-11 pmid: 28980559

102. Cehajic-Kapetanovic J, Birtel J, McClements ME, Shanks ME, Clouston P, Downes SM, et al. Clinical and Molecular Characterization of PROM1-Related Retinal Degeneration. JAMA Netw Open. 2019;2(6):e195752. doi: 10.1001/jamanetworkopen.2019.5752 pmid: 31199449

103. Palmowski-Wolfe A, Stingl K, Habibi I, Schorderet D, Tran HV. Novel PDE6B Mutation Presenting with Retinitis Pigmentosa A Case Series of Three Patients. Klin Monbl Augenheilkd. 2019;236(4):562-7. doi: 10.1055/a-0811-5480 pmid: 30646425

104. Tsang SH, Sharma T. Retinitis Pigmentosa (Non-syndromic). Adv Exp Med Biol. 2018;1085:125-30. doi: 10.1007/978-3-31995046-4_25 pmid: 30578498

105. Tatour Y, Tamaiev J, Shamaly S, Colombo R, Bril E, Rabinowitz T, et al. A novel intronic mutation of PDE6B is a major cause of autosomal recessive retinitis pigmentosa among Caucasus Jews. Mol Vis. 2019;25:155-64. pmid: 30820151

106. Souzeau E, Thompson JA, McLaren TL, De Roach JN, Barnett $\mathrm{CP}$, Lamey TM, et al. Maternal uniparental isodisomy of chromosome 6 unmasks a novel variant in TULP1 in a patient with early-onset retinal dystrophy. Mol Vis. 2018;24:478-84. pmid: 30090012

107. Ajmal M, Khan MI, Micheal S, Ahmed W, Shah A, Venselaar $\mathrm{H}$, et al. Identification of recurrent and novel mutations in TULP1 in Pakistani families with early-onset retinitis pigmentosa. Mol Vis. 2012;18:1226-37. pmid: 22665969

108. Ullah I, Kabir F, Iqbal M, Gottsch CB, Naeem MA, Assir MZ, et al. Pathogenic mutations in TULP1 responsible for retinitis pigmentosa identified in consanguineous familial cases. Mol Vis. 2016;22:797-815. pmid: 27440997

109. Kannabiran C, Singh H, Sahini N, Jalali S, Mohan G. Mutations in TULP1, NR2E3, and MFRP genes in Indian families with autosomal recessive retinitis pigmentosa. Mol Vis. 2012;18:1165-74. pmid: 22605927

110. Heon E, Kim G, Qin S, Garrison JE, Tavares E, Vincent A, et al. Mutations in C8ORF37 cause Bardet Biedl syndrome (BBS21). Hum Mol Genet. 2016;25(11):2283-94. doi: 10.1093/hmg/ddw096 pmid: 27008867

111. Khan AO, Decker E, Bachmann N, Bolz HJ, Bergmann C. C8orf37 is mutated in Bardet-Biedl syndrome and constitutes a locus allelic to non-syndromic retinal dystrophies. Ophthalmic Genet. 2016;37(3):290-3. doi: 10.3109/13816810.2015.1066830 pmid: 26854863

112. Wang J, Zhou C, Xiao Y, Liu H. Novel splice receptor-site mutation of RPGR in a Chinese family with X-linked retinitis pigmentosa. Medicine (Baltimore). 2018;97(41):e12779. doi 10.1097/MD.0000000000012779 pmid: 30313097

113. Haddad MF, Khabour OF, Abuzaideh KA, Shihadeh W. Screening for mutations in RPGR and RP2 genes in Jordanian families with X-linked retinitis pigmentosa. Genet Mol Res. 2016;15(2). doi: 10.4238/gmr.15027842 pmid: 27323122

114. Beltran WA, Cideciyan AV, Lewin AS, Hauswirth WW, Jacobson SG, Aguirre GD. Gene augmentation for X-linked retinitis pigmentosa caused by mutations in RPGR. Cold Spring Harb Perspect Med. 2014;5(2):a017392. doi: 10.1101/cshperspect.a017392 pmid: 25301933

115. Sengillo JD, Fridman G, Cho GY, Buchovecky C, Tsang SH. Novel Mutation in Retinitis Pigmentosa GTPase Regulator Gene Causes Primary Ciliary Dyskinesia and Retinitis Pigmentosa. Ophthalmic Surg Lasers Imaging Retina. 2018;49(7):548-52. doi: 10.3928/23258160-20180628-14 pmid: 30021045

116. Talib $M$, van Schooneveld MJ, Thiadens AA, Fiocco $M$, Wijnholds J, Florijn RJ, et al. Clinical and genetic characteristics of male patients with RPGR-associated retinal dystrophies: A LongTerm Follow-up Study. Retina. 2019;39(6):1186-99. doi: 10.1097/IAE.0000000000002125 pmid: 29528978

117. Huang L, Mao Y, Yang J, Li Y, Li Y, Yang Z. Mutation screening of the USH2A gene in retinitis pigmentosa and USHER patients in a Han Chinese population. Eye (Lond). 2018;32(10):1608-14. doi: 10.1038/s41433-018-0130-3 pmid: 29899460

118. Zhao Y, Hosono K, Suto K, Ishigami C, Arai Y, Hikoya A, et al. The first USH2A mutation analysis of Japanese autosomal recessive retinitis pigmentosa patients: a totally different mutation profile with the lack of frequent mutations found in Caucasian patients. J Hum Genet. 2014;59(9):521-8. doi: 10.1038/jhg.2014.65 pmid: 25078356

119. Nagase Y, Kurata K, Hosono K, Suto K, Hikoya A, Nakanishi $\mathrm{H}$, et al. Visual Outcomes in Japanese Patients with Retinitis Pigmentosa and Usher Syndrome Caused by USH2A Mutations. Semin Ophthalmol. 2018;33(4):560-5. doi: 10.1080/08820538.2017.1340487 pmid: 28678594

120. Fu YC, Chen N, Qiu ZL, Liu L, Shen J. Compound pathogenic mutation in the USH2A gene in Chinese RP families detected by wholeexome sequencing. Mol Med Rep. 2018;18(6):5016-22. doi: 10.3892/mmr.2018.9530 pmid: 30280194 
121. Aleman TS, Uyhazi KE, Serrano LW, Vasireddy V, Bowman SJ, Ammar MJ, et al. RDH12 Mutations Cause a Severe Retinal Degeneration With Relatively Spared Rod Function. Invest Ophthalmol Vis Sci. 2018;59(12):5225-36. doi: 10.1167/iovs.1824708 pmid: 30372751

122. Gao T, Tian C, Hu Q, Liu Z, Zou J, Huang L, et al. Clinical and Mutation Analysis of Patients with Best Vitelliform Macular Dystrophy or Autosomal Recessive Bestrophinopathy in Chinese Population. Biomed Res Int. 2018;2018:4582816. doi: 10.1155/2018/4582816 pmid: 30498755

123. Guo J, Gao F, Tang W, Qi Y, Xuan Y, Liu W, et al. Novel Best1 Mutations Detected by Next-Generation Sequencing in a Chinese Population with Vitelliform Macular Dystrophy. Retina. 2019;39(8):1613-22. doi: 10.1097/IAE.0000000000002183 pmid: 29781975

124. Dalvin LA, Abou Chehade JE, Chiang J, Fuchs J, lezzi R, Marmorstein AD. Retinitis pigmentosa associated with a mutation in BEST1. Am J Ophthalmol Case Rep. 2016;2:11-7. doi: 10.1016/j.ajoc.2016.03.005 pmid: 29503890

125. Eblimit A, Nguyen TM, Chen $\mathrm{Y}$, Esteve-Rudd J, Zhong $\mathrm{H}$, Letteboer S, et al. Spata7 is a retinal ciliopathy gene critical for correct RPGRIP1 localization and protein trafficking in the retina. Hum Mol Genet. 2015;24(6):1584-601. doi: 10.1093/hmg/ddu573 pmid: 25398945

126. Mahajan D, Votruba M. A novel NR2E3 gene mutation in autosomal recessive retinitis pigmentosa with cystic maculopathy. Acta Ophthalmol. 2018;96(4):e535-e6. doi: 10.1111/aos.13629 pmid: 29193891

127. Sato S, Morimoto T, Hotta K, Fujikado T, Nishida K. A novel compound heterozygous mutation in TTC8 identified in a Japanese patient. Hum Genome Var. 2019;6:14. doi: 10.1038/s41439-019-0045-y pmid: 30886724

128. Fingert JH, Oh K, Chung M, Scheetz TE, Andorf JL, Johnson $\mathrm{RM}$, et al. Association of a novel mutation in the retinol dehydrogenase 12 (RDH12) gene with autosomal dominant retinitis pigmentosa. Arch Ophthalmol. 2008;126(9):1301-7. doi: 10.1001/archopht.126.9.1301 pmid: 18779497

129. Kohl S, Coppieters F, Meire F, Schaich S, Roosing S, Brennenstuhl $\mathrm{C}$, et al. A nonsense mutation in PDE6H causes autosomal-recessive incomplete achromatopsia. Am J Hum Genet. 2012;91(3):527-32. doi: 10.1016/j.ajhg.2012.07.006 pmid: 22901948

130. Arshad MW, Lee Y, Malik MA, Khan J, Khan A, Kareem A, et al. Identification of Novel Mutation in CNGA3 gene by Whole-
Exome Sequencing and In-Silico Analyses for Genotype-Phenotype Assessment with Autosomal Recessive Achromatopsia in Pakistani families. J Pak Med Assoc. 2019;69(2):183-9. pmid: 30804581

131. Sun $W$, Zhang $Q$. Diseases associated with mutations in CNGA3: Genotype-phenotype correlation and diagnostic guideline. Prog Mol Biol Transl Sci. 2019;161:1-27. doi: 10.1016/bs.pmbts.2018.10.002 pmid: 30711023

132. Mayer AK, Van Cauwenbergh C, Rother C, Baumann B, Reuter $\mathrm{P}$, De Baere $\mathrm{E}$, et al. CNGB3 mutation spectrum including copy number variations in 552 achromatopsia patients. Hum Mutat. 2017;38(11):1579-91. doi: 10.1002/humu.23311 pmid: 28795510

133. Pascual-Camps I, Barranco-Gonzalez H, Avino-Martinez J, Silva E, Harto-Castano M. Diagnosis and Treatment Options for Achromatopsia: A Review of the Literature. J Pediatr Ophthalmol Strabismus. 2018;55(2):85-92. doi: 10.3928/01913913-2017111701 pmid: 29257187

134. Li S, Huang L, Xiao X, Jia X, Guo X, Zhang Q. Identification of CNGA3 mutations in 46 families: common cause of achromatopsia and cone-rod dystrophies in Chinese patients. JAMA Ophthalmol. 2014;132(9):1076-83. doi: 10.1001/jamaophthalmol.2014.1032 pmid: 24903488

135. Guo LY, Zheng SL, Li J, Zhu Q, Duan WH, Zhang Y, et al. Phenotypic variability of SLC7A14 mutations in patients with inherited retinal dystrophy. Ophthalmic Genet. 2019;40(2):11823. doi: 10.1080/13816810.2019.1586964 pmid: 30924391

136. Sugahara M, Oishi M, Oishi A, Ogino K, Morooka S, Gotoh $\mathrm{N}$, et al. Screening for SLC7A14 gene mutations in patients with autosomal recessive or sporadic retinitis pigmentosa Ophthalmic Genet. 2017;38(1):70-3. doi: 10.3109/13816810.2015.1136336 pmid: 27028480

137. Jinda W, Poungvarin N, Taylor TD, Suzuki $Y$, Thongnoppakhun $\mathrm{W}$, Limwongse $\mathrm{C}$, et al. A novel start codon mutation of the MERTK gene in a patient with retinitis pigmentosa. Mol Vis. 2016;22:342-51. pmid: 27122965

138. Audo I, Mohand-Said S, Boulanger-Scemama E, Zanlonghi X Condroyer C, Demontant V, et al. MERTK mutation update in inherited retinal diseases. Hum Mutat. 2018;39(7):887-913. doi: 10.1002/humu.23431 pmid: 29659094

139. Liu S, Bi JG, Hu Y, Tang D, Li B, Zhu P, et al. Targeted next generation sequencing identified novel loss-of-function mutations in MERTK gene in Chinese patients with retinitis pigmentosa. Mol Genet Genomic Med. 2019;7(4):e00577. doi: 10.1002/mgg3.577 pmid: 30790467 